NBER WORKING PAPER SERIES

\title{
THE RESPONSE OF THE INFORMAL SECTOR TO TRADE LIBERALIZATION
}

\author{
Pinelopi K. Goldberg \\ Nina Pavenik \\ Working Paper 9443 \\ http://www.nber.org/papers/w9443
NATIONAL BUREAU OF ECONOMIC RESEARCH
1050 Massachusetts Avenue
Cambridge, MA 02138
January 2003

\begin{abstract}
We wish to thank Hector Mejia at DANE and Andreas Blom at the World Bank for providing us with the data. We are also grateful to Cristina Gamboa, Adriana Kugler, and Ximena Pena for answering our numerous questions about the data and the Colombian reforms, and Steve Bronars, Eric Edmonds, Sebastian Edwards, Doug Marcouiller, Dani Rodrik and participants at the NBER Inter-American Seminar on Economics in Monterrey, Mexico for useful comments and suggestions. The authors gratefully acknowledge financial support from the National Science Foundation Grant SES \#0213459. Pavcnik also acknowledges the support from the Rockefeller Social Science Faculty Grant. The views expressed herein are those of the authors and not necessarily those of the National Bureau of Economic Research.

(C)2003 by Pinelopi K. Goldberg and Nina Pavcnik. All rights reserved. Short sections of text not to exceed two paragraphs, may be quoted without explicit permission provided that full credit including . notice, is given to the source.
\end{abstract}


The Response of the Informal Sector to Trade Liberalization

Pinelopi K. Goldberg and Nina Pavcnik

NBER Working Paper No. 9443

January 2003

JEL No. F10, F13, J31

\section{$\underline{\text { ABSTRACT }}$}

This paper studies the relationship between trade liberalization and informality. It is often claimed that increased foreign competition in developing countries leads to an expansion of the informal sector, defined as the sector that does not comply with labor market legislation. Using data from two countries that experienced large trade barrier reductions in the 1980's and 1990's, Brazil and Colombia, we examine the response of the informal sector to liberalization. In Brazil, we find no evidence of a relationship between trade policy and informality. In Colombia, we do find evidence of such a relationship, but only for the period preceding a major labor market reform that increased the flexibility of the Colombian labor market. These results point to the significance of labor market institutions in assessing the effects of trade policy on the labor market.

Pinelopi K. Goldberg Department of Economics

Yale University

37 Hillhouse Avenue

P.O. Box 208264

New Haven, CT 06520-8264

and NBER

penny.goldberg@yale.edu
Nina Pavcnik

Department of Economics

Dartmouth College

6106 Rockefeller Center

Hanover, NH 03755

and NBER

nina.pavcnik@dartmouth.edu 


\section{Introduction}

During the 1980's and early 1990's many Latin American economies drastically cut tariff and non-tariff barriers, and opened their markets to foreign competition. While this massive trade liberalization was celebrated as contributing to economic growth and efficiency, many have expressed fears that it may have widened the gap between the poor and rich in these countries. This paper focuses on one particular concern: that trade reforms led to a reallocation from the formal to informal sector (Stallings and Peres (2000)). The informal sector is conventionally defined as the sector of the economy that does not comply with labor market legislation and does not provide worker benefits. It is primarily comprised of small firms. A broader definition includes temporary, or part-time workers employed in formal establishments. The size of the informal sector is significant in many developing countries; in Colombia, for example, it is estimated that $50-60 \%$ of the labor force are employed in the informal sector. Because this sector is often identified with worse working conditions and lower job "quality", a reallocation of employment from the formal to informal sector is considered undesirable. Naturally, such claims are controversial. To the extent that employment in the informal sector is voluntary and mainly sought by those placing a high value on flexible hours, informality is not necessarily an inferior option.

We believe that a study of the impact of trade reforms on the informal sector is worthwhile for two reasons. First, despite the prominence of this question in public debate, there is hardly any empirical evidence linking increases in informal employment to trade policy - the only exception being a study by Currie and Harrison (1997) on Morocco that finds that firms started hiring more temporary workers after the completion of a comprehensive trade liberalization program. Second, we view this study as part of a larger effort to understand how the labor market in developing countries adjusts to trade reforms. In our earlier work on Colombia (see Goldberg and Pavcnik (2001), and Attanasio, Goldberg and Pavcnik (2002)), we document that there is little labor reallocation across industries in the aftermath of trade reforms; in contrast, there is evidence that industry wages respond to trade liberalization in a manner consistent with the predictions of the specific factors model, or, alternatively, the loss of industry rents: wage premia decline in those industries in which the tariff cuts were largest. The stability of industry employment shares is surprising. While such stability may be indicative of mobility costs and other labor market rigidities, an alternative explanation that we put forward in our 
previous work is that the informal sector provides an additional margin of adjustment, possibly within industries. In this paper we attempt a more rigorous investigation of this hypothesis.

The usual argument that trade liberalization leads to a rise in informality goes something like follows: Trade reforms expose formal establishments to increased foreign competition. In response, such establishments try to reduce labor costs by cutting worker benefits, replacing permanent workers with part-time labor, or subcontracting with establishments in the informal sector, including home-based and self-employed microenterpreneurs. Alternatively, firms in the formal sector may respond to the intensified competition from abroad by laying off workers who subsequently seek employment in the informal sector.

From a theoretical point of view, the problem with this argument is that it immediately raises the question of why profit-maximizing firms had not switched to informal employment prior to the reforms in order to reduce costs. We start our analysis by presenting a theoretical model that can potentially be used to justify the view expressed above. Our theoretical discussion is based on the efficiency wage models considered in Shapiro and Stiglitz (1984) and Bulow and Summers (1986), and the dynamic extension of these models discussed in Saint-Paul (1996). We use this framework to conduct comparative statics, and assess how permanent trade liberalization would alter the optimal share of informal employment. Consistent with the claims presented above, the model implies that trade liberalization should lead to an increase of informal employment.

We should emphasize that we do not view the theoretical model we present as the only possible explanation for the existence of an informal sector. One can certainly write down alternative models (for example one in which wage differences across the formal and informal sectors represent compensating differentials), which would have different, possibly even opposite implications for the impact of trade reforms on informality. But such models would not represent the thinking of those who associate free trade with a larger informal sector. The purpose of our model is simply to capture this thinking, and present it in a logically consistent way. Put differently, the point of the theoretical analysis is to demonstrate that the view that trade reforms can lead to increased informality can be theoretically justified. Whether or not it is relevant in practice is however an empirical question, and to answer this question is the goal of the empirical part of our paper. In the same spirit, we should also emphasize that our empirical analysis does not aim at "testing" the theory against alternative hypotheses. The objective is 
rather to estimate the effects of trade liberalization on informality in order to assess whether the fears expressed above are justified.

Our empirical analysis focuses on Colombia and Brazil, two countries that experienced major trade liberalization episodes in the last two decades. Both countries are characterized by the presence of a large informal sector. Moreover, the proportion of workers employed in the informal sector has increased over time, peaking in the late 1990's. It is this trend that has led some to believe that intensified foreign competition could be contributing to the rise in informality.

Inferences based on this macroeconomic trend are however misleading for several reasons. First, the trend may be due to the expansion of the non-tradable service sector, which is characterized by a larger share of informality. Second, it could partially reflect firms' response to the recession of the late 1990's. More importantly, both Colombia and Brazil experienced a series of other reforms during the late 1980s and 1990's; among them, the most notable ones concern changes in labor market regulation. In Colombia, these reforms introduced more flexibility in labor markets, as they decreased firms' hiring and firing costs, and very likely affected firms' incentives to employ informal workers. In a series of papers, Kugler shows that the labor market deregulation in Colombia led to an increase in formal employment. These results raise the concern that the partial overlap of labor market with trade reforms may prevent us from finding any effects of trade liberalization on informality, since the two sets of reforms are presumed to have opposite effects on the share of the informal sector (labor market reforms supposedly reduce informality, while trade reforms increase it).

Fortunately, the nature of the trade reforms during this period is such that the effect of trade policy changes on informality can be identified off the cross-sectional variation of trade policy changes in our data. Trade liberalization in Colombia and Brazil did not just reduce protection rates, but also changed the structure of protection in these countries. One of the great advantages of focusing on Colombia and Brazil is that, because these countries were not members of the GATT or WTO prior to trade liberalization, they used tariff rates as the main trade policy instrument. Tariff rates are both well measured (relative to the non-tariff barriers traditionally employed in more developed economies), and comparable across time. The trade reforms affected tariff rates differentially in different sectors. Sectors that had traditionally received high protection rates, such as textiles and apparel, experienced the largest tariff cuts. In 
contrast, sectors with relatively low rates of protection experienced smaller tariff cuts. It is this differential rate of tariff declines across industries that we exploit in order to identify the effects of tariff changes on informality. A further advantage of focusing on countries that were not WTO members prior to the trade reforms, is that the usual concerns about the endogeneity of trade policy changes and political economy of protection are less pronounced here than in other studies. This is because the government's objective when reducing tariff rates across industries is to achieve the uniform tariff rate negotiated with the WTO (in the case of Colombia, for example, this rate is $13 \%$ ). Policy makers are accordingly less concerned with catering to special lobby interests; as we demonstrate in our earlier work (see Goldberg and Pavcnik (2001) for Colombia, and Pavcnik, Blom, Goldberg, and Schady (2002) for Brazil), tariff declines in each industry are proportional to the industry's pre-reform tariff level in 1983.

The basic premise underlying our analysis is that mobility across the formal and informal sectors within an industry is greater than mobility across industries. The descriptive statistics we present in the empirical section seem to support this premise; during the 1986-1998 period, approximately $88 \%$ of the change in the aggregate share of informal workers in Colombia (100\% in Brazil) is accounted for by "within", as opposed to "between-industry" shifts. The results of our earlier work concerning the stability of industry employment shares are also consistent with this view. To identify the effects of tariff changes in each country on the informal sector we relate changes in the likelihood of informal employment to tariff changes in each sector; thus, we only rely on within industry variation to identify the effects of the trade reforms on informality. This approach presumes that, while the effect of trade liberalization varied across industries, the effect of labor market reforms did not vary in a systematic way across industries. While this is certainly open to debate, we are not aware of any arguments or evidence that the effects of labor market reforms on informality varied across industries, or, more importantly, that they were systematically related to tariff cuts in each industry.

To preview our results, we find little evidence that the informal sector was impacted by trade policy in any significant manner. For the case of Brazil, our attempts to link trade reforms to increases in informal employment have simply failed. In Colombia, we find some weak evidence that in the early years of our sample, prior to the labor reform, trade liberalization contributed to an increase in informal employment in those sectors where the tariff cuts were largest. However, the effects are small. For the period following the labor reform, we again find 
no link between trade and informality. These results suggest that trade policy is likely a second order concern compared to labor market legislation. Moreover, the trade policy effects are dependent on the labor market institutions. When labor market rigidities are significant, as is the case with Colombia in the early years, firms are more likely to respond to intensified competition by reducing formal employment.

The remainder of the paper is organized as follows. Section 2 presents the theoretical model. In section 3 we provide some background on Colombia and Brazil, and the trade reforms implemented in these two countries, and discuss our data sources. In section 4 we discuss the labor market institutions in the two countries and emphasize the differences that may account for the differences in our empirical results. Section 5 contains some descriptive results on informality, quality of work, and changes in informality over time and across and within industries. Section 6 discusses our empirical results, and section 7 concludes.

\section{Trade and Informality: Theory}

The first question our analysis needs to address is why firms keen to maximize profits had not made wider use of informal workers prior to the reforms, if such workers were indeed associated with lower labor costs. Saint-Paul's (1994) dynamic efficiency wage model provides a possible justification for the simultaneous use of formal and informal workers, and is - in our view - best suited to describe and formalize the thinking underlying the argument that trade liberalization will lead to an increase in informality.

The basic structure of the models is as follows. Consider an infinite-horizon firm that faces uncertain demand. In each period, the firms' revenue $R_{t}$ is given by:

$$
R_{t}=p_{t} f\left(l_{t}\right)
$$

where $p_{t}$ denotes the firm's price in period $t, f$ is a concave, increasing production function, and $l_{t}$ denotes the level of employment. The price $p_{t}$ is a random variable, with a cumulative density function $G(p)$, and $G^{\prime}=g$. For expositional purposes we assume that the $p_{t}$ 's are i.i.d. This assumption can however easily be relaxed to accommodate different degrees of persistence in the price shocks. Furthermore, we assume that the price shock in period $t+1$ is known at the end of period $t$, so that $l_{t+1}$ is known one period ahead. This assumption is again made to facilitate exposition, but the results do not critically depend on it. 
The assumptions that are central to the analysis are the following: (1) The firm faces demand uncertainty. (2) The firm can hire workers from two pools: a pool of formal, and a pool of informal workers; informal workers are defined broadly to encompass both part-time or temporary workers employed within a firm, and small firms and individuals who may subcontract with a formal firm. (3) The two pools differ in two important aspects: First, the employment of formal workers is regulated by labor market legislation; such workers receive benefits, cannot be dismissed unless the firm has accumulated sufficient evidence, and receive severance pay when dismissed. This implies that the adjustment cost associated with the employment of such workers is higher compared to the employment of informal workers, which is not governed by any legislation. Second, the effort of informal workers can be monitored perfectly, at some constant unit cost $m$. In contrast, the activities of formal workers cannot be monitored. Note that this difference does not arise from any differences in the characteristics of formal and informal workers (though such differences, e.g., differences in skill, experience, etc., can be built-in into extensions of the model); formal and informal workers are assumed to be equivalent in every respect. A potential justification for the difference in monitoring costs across formal and informal workers is the very existence of labor market regulation. Because firms need to accumulate extensive evidence to justify firing formal workers, the cost of effectively monitoring such workers (to meet the standard dictated by unjust dismissal legislation) is substantial, so that firms may prefer to use alternative strategies to motivate such workers.

The model can be solved for the optimal shares of formal and informal workers. It can be shown that firms will generally find it optimal to simultaneously employ formal and informal workers. The main steps in the solution are the following:

\section{a. Wages and Labor Cost}

Consider the wage determination process first. Since informal workers can be monitored perfectly, they will be paid their reservation wage, $w_{I}=R$, and the total cost of employing $l_{t}{ }^{I}$ informal workers in period $t$ will be:

$$
c\left(l_{t}^{I}\right)=\left(w_{I}+m\right) l_{t}^{I}
$$

Next, consider the wages in the formal sector. Given that formal workers are not monitored, they will have incentives to shirk. To prevent shirking, the firm offers efficiency wages. Specifically, 
the optimal wage for formal workers is determined by the familiar no-shirking condition that equalizes the expected utility associated with shirking, with the expected utility associated with no-shirking. It is easy to show that this condition ultimately leads to the following wage equation for formal workers:

$$
w_{F}=a+\frac{b}{1-\phi_{t-1}}=R-\frac{1}{x}+\frac{1}{\delta x} \frac{1}{1-\phi_{t-1}}
$$

where $\delta$ stands for the discount rate; $x$ denotes the probability of catching (and firing) a shirker; $\phi_{t}$ is the probability that a worker loses her job for reasons other than shirking (with a uniform firing rule $\left.\phi_{t}=\max \left\{\frac{l_{t}^{F}-l_{t+1}^{F}}{l_{t}^{F}}, 0\right\}\right) ; a$ and $b$ are constants, equal to $a=R-\frac{1}{x}$, and $b=\frac{1}{\delta x}$ respectively. The above wage equation implies that the cost of employing $l_{t}^{F}$ formal workers in period $t$ is:

$$
c\left(l_{t}^{F}\right)=a l_{t}^{F}+b \max \left(l_{t}^{F}, l_{t-1}^{F}\right)
$$

There are two features of the results so far that are worth noting. First, wages in the formal sector are higher than in the informal sector, even though workers have the same qualifications. The term $\frac{1}{x}\left(\frac{1}{\delta} \frac{1}{1-\phi_{t-1}}-1\right)>0$ represents the rent to formality. The reason for this rent is that - in the absence of monitoring - firms need to penalize formal workers who shirk. Since the penalty from being caught shirking is losing one's job, the existence of efficiency wages in the formal sector implies that workers who are fired, are made strictly worse off.

Second, note that this setup implies a kink in the labor cost function at $l_{t+1}{ }^{F}=l_{t}{ }^{F}$. The cost of hiring an additional worker $\left(l_{t+1}{ }^{F}>l_{t}^{F}\right)$ is higher than the cost of not hiring. In particular, the marginal cost of labor is equal to $a+b$, if $l_{t+1}{ }^{F}>l_{t}{ }^{F}$, and $a$ if $l_{t+1}{ }^{F} \leq l_{t}{ }^{F}$. Put in a different way, efficiency wages introduce an adjustment cost, because the expectation of being fired raises the wage that needs to be paid to prevent workers from shirking.

\section{b. The Firm's Optimization Problem}

At the end of period $t$ the firm decides how many formal and informal workers to employ in $t+1$. The value of the firm is: 
$V\left(l_{t}^{F}, p_{t+1}\right)=\max _{l_{t+1}^{I}, l_{t+1}} p_{t+1} f\left(l_{t+1}^{F}+l_{t+1}^{I}\right)-c\left(l_{t+1}^{F}, l_{t}^{F}\right)-\left(w_{I}+m\right) l_{t+1}^{I}+\delta E_{t} V\left(l_{t+1}^{F}, p_{t+2}\right)$

Note that since the informal labor force $l_{t}{ }^{I}$ does not have an influence on the value of the firm at the beginning of period $t+1$, the only state variable is $l_{t}^{F}$. The first order conditions characterizing the optimal solution are given by:

FOC with respect to $l_{t+1}{ }^{I}$ :

$$
\begin{array}{ll}
p_{t+1} f^{\prime}\left(l_{t+1}^{F}+l_{t+1}^{I}\right)=w_{I}+m & \text { if } p_{t+1} f^{\prime}\left(l_{t+1}^{F}\right)>w_{I}+m, \\
l_{t+1}^{I}=0 & \text { if } p_{t+1} f^{\prime}\left(l_{t+1}^{F}\right)<w_{I}+m
\end{array}
$$

FOC with respect to $l_{t+1}^{F}$ :

Define $k\left(l_{t+1}^{F}\right)=\frac{E_{t} \partial V\left(l_{t+1}^{F}, p_{t+2}\right)}{\partial l_{t+1}^{F}}$. Given the kink in the labor cost function for formal workers, one needs to distinguish between three cases in deriving the FOC:

Case 1: $p_{t+1} f^{\prime}\left(l_{t}^{F}+l_{t+1}^{I}\right)+\delta k\left(l_{t}^{F}\right)>a+b$, so that $l_{t+1}^{F}>l_{t}^{F}$ In this case the FOC is given by:

$$
p_{t+1} f^{\prime}\left(l_{t+1}^{F}+l_{t+1}^{I}\right)+\delta k\left(l_{t+1}^{F}\right)=a+b
$$

Case 2: $p_{t+1} f^{\prime}\left(l_{t}^{F}+l_{t+1}^{I}\right)+\delta k\left(l_{t}^{F}\right)<a$ so that $l_{t+1}^{F}<l_{t}^{F}$

In this case the FOC is given by:

$$
p_{t+1} f^{\prime}\left(l_{t+1}^{F}+l_{t+1}^{I}\right)+\delta k\left(l_{t+1}^{F}\right)=a
$$

Case 3: $a \leq p_{t+1} f^{\prime}\left(l_{t}^{F}+l_{t+1}^{I}\right)+\delta k\left(l_{t}^{F}\right) \leq a+b$. In this case $l_{t+1}^{F}=l_{t}^{F}$

\section{c. The Optimal Shares of Formal and Informal Workers}

Given this structure, it can be shown that there exists a number $\tilde{l}$ such that the firm will employ at most $\tilde{l}$ formal workers. This number is determined by the equation

$$
\delta k(\widetilde{l})=a+b-w_{I}-m,
$$


or equivalently ${ }^{1}$ :

$$
a+b-w_{I}-m=-\delta f^{\prime}(\tilde{l}) \int_{\underline{p}}^{\bar{p}} G(p) d p
$$

where $\bar{p}=\left(w_{I}+m\right) / f^{\prime}(l)$, and $p=\left(w_{I}+m-b\right) / f^{\prime}(l)$. The value $\tilde{l}$ has the following interpretation: If the firm has a number of formal workers that is less than $\tilde{l}$, it will not start hiring informal workers until the employment of formal workers reaches the value $\tilde{l}^{2}$ When the firm has no informal workers, it operates as a purely formal firm. Vice versa, if the firm operates in a dual zone, employing both formal and informal workers, it will not start firing formal workers until all informal workers are fired first (that is if $l_{t+1} F<\tilde{l}$, then $l_{t+1}{ }^{I}=0$ ). Whether or not the firm employs informal workers, depends on the value of the shock $p_{t+1}$. If the shock is large enough, the firm will find it profitable to expand into the informal sector. Note that whenever the firm employs informal workers, the marginal product of labor is, according to (1), pinned down by the marginal cost of these workers $\left(w_{I}+m\right)$. Hence, it does not depend on the current value of the shock $p_{t+1}$. This implies that a change in $p_{t+1}$ is met with a change in labor force, using informal workers as the adjustment margin, so that the marginal product remains constant and equal to $w_{I}+m$. The same logic implies that the informal workers are the first to go, when the firm is hit with a negative shock. Formal workers are relatively sheltered from negative shocks; only when shocks are negative enough to prompt the firm to fire all its informal workers will formal workers be affected.

\section{d. The Effects of Trade Liberalization}

We are now ready to analyze the effects of a reduction in trade barriers on the size of the informal sector. The first question that arises is how such a reduction enters the model. One possible approach is to model trade liberalization as a negative price shock. As noted above, a straightforward implication of the dynamic efficiency wage model is that the firm would react by laying off its informal workers first, while keeping its formal work force intact. After all, this

\footnotetext{
${ }^{1}$ The derivation is quite involved and can be found in the Appendix of Chapter 4 in Saint-Paul (1996).

${ }^{2}$ There is an implicit assumption underlying the following analysis that the unit cost of informal labor $\left(w_{I}+m\right)$ exceeds the minimum efficiency wage $(a+b)$. Otherwise the firm would employ only informal workers.
} 
flexibility to let the informal workers go when times are bad is central to explaining the existence of the informal sector. Only if the shock is sufficiently negative, will formal workers be affected. Empirically, we would then expect the share of formal workers in total employment to increase as the firm adjusts to the negative shock.

This interpretation of trade liberalization is however unsatisfactory for two reasons. First, the derived implication, namely that trade reforms lead to an increase in the share of employed formal workers, is exactly the opposite of what opponents of such reforms fear. But the sole purpose of our model was to provide a justification for their claims based on economic theory. This goal is clearly not achieved if the analysis presented above yields the opposite conclusion. Second, the interpretation of the trade reforms in Brazil and Colombia as a one-time negative demand shock is inconsistent with the nature of these reforms. The trade reforms were implemented as part of these countries' entry into the WTO; therefore they were permanent. This suggests that a more appropriate interpretation of trade liberalization is as a process that leads to an increase in the cumulative distribution function $G(p)$.

Specifically, we assume that the trade reforms lead to a new distribution function $G^{*}(p)$, such that $G^{*}(p)>G(p)$, for all $p$. This implies that the expected value of $p$ is lower using $G^{*}(p)$ than $G(p): E_{G^{*}}(p)<E_{G}(p)$. We believe that this modeling approach accurately reflects the effects of a permanent decrease of trade barriers, as such a decrease leads to price declines in the affected industries. While prices remain volatile, they are expected to be on average lower once the trade reforms are implemented.

The effect of trade liberalization on the size of the informal sector can be derived by differentiating the right hand side of (6) with respect to $G(p)$. Remember that $\bar{p}=\left(w_{I}+m\right) / f^{\prime}(l)$, and $\underline{p}=\left(w_{I}+m-b\right) / f^{\prime}(l)$. Differentiation of (6) yields:

$$
\begin{aligned}
& \frac{d \tilde{l}}{d G(p)}=-\delta b /\left\{\delta f^{\prime \prime}(\tilde{l}) \int_{(\underline{p})}^{(\bar{p})} G(p) d p-\delta\left(w_{I}+m\right) f^{\prime \prime}(\tilde{l}) / f^{\prime}(\tilde{l})[G(\bar{p})-G(\underline{p})+b G(\underline{p})]\right\} \\
& =-\delta b f^{\prime}(\tilde{l}) / f^{\prime \prime}(\tilde{l})\left\{\delta f^{\prime}(\tilde{l}) \int_{(\underline{p})}^{(\bar{p})} G(p) d p-\delta\left(w_{I}+m\right)[G(\bar{p})-G(\underline{p})+b G(\underline{p})]\right\}
\end{aligned}
$$


Taking into account that $b>0, f^{\prime}(l)>0, f^{\prime \prime}(l)<0$, and that from (6) $\delta f^{\prime}(\tilde{l}) \int^{(\bar{p})} G(p) d p=-\left(a+b-w_{I}-m\right)$, so that the term in the curly brackets is negative, it is easy $(\underline{p})$

to show that $\frac{d \tilde{l}}{d G(p)}<0$, so that an increase in $G$ will be matched by a lower value of $\tilde{l}$. This is precisely the effect described in the verbal argument in the introduction: trade liberalization leads to a decline in the optimal number of formal workers, and an expansion of the informal sector. From (7), the larger $b$ is, the larger the effect of the reforms on the optimal size of the formal sector. Note that $b$ is inversely related to the probability of firing formal workers because of shirking $\left(b=\frac{1}{\delta x}\right)$. Taking the probability of detecting and firing shirkers as a proxy for the severity of firing restrictions, the implication is then that the stricter labor market legislation is (that is, the smaller the probability of detection of shirking $x$ is), the larger the impact of trade liberalization on reallocation from the formal to the informal sector will be.

Note that the analysis above focused on the effects within representative firms of specific industries, thus ignoring general equilibrium effects. In the general equilibrium, the effects of trade policy on informality could potentially differ, as workers move from industries with large trade barrier reductions towards industries that are less affected by trade liberalization. If the expanding industries were industries that typically employ a larger share of formal workers, then it is possible that trade liberalization would lead to an increase of formal employment in the aggregate. And vice versa, if the workers moved towards industries employing more informal workers (e.g., the service sector), we would have an increase in informality, which, however, would be driven by labor re-allocation across industries rather than the mechanism outlined above. While our theoretical discussion abstracts from such effects, in the empirical analysis we try to assess the importance of general equilibrium effects by decomposing changes in informality into "within" and "between" industry changes (see discussion in section 5). Our results suggest that in Brazil "within" industry shifts account for $88 \%$ of the changes in the share of informal workers, while in Colombia this number is close to $100 \%$. We therefore believe that general equilibrium effects, though in theory important, are in practice of secondary importance in explaining changes in informal employment. 
We now turn to the empirical part of the analysis to examine whether the implications of this section are borne out in the data.

\section{Data and Background}

\subsection{Trade Policy}

During the 1980s and 1990s, Brazil and Colombia implemented large trade liberalization programs. Prior to the reforms, both countries followed import-substitution trade policies that protected domestic producers from foreign competition with high levels of tariffs and non-tariff barriers to trade (NTBs). The degree of protection varied widely across industries. For example, clothing faced tariffs of over 100\% in Brazil in 1987 (over 90\% in Colombia in 1984), while petrochemicals faced a $32 \%$ tariff in Brazil, and chemicals had a $26 \%$ tariff in Colombia in 1984. ${ }^{3}$ The pattern of protection suggests that Brazil and Colombia protected relatively unskilled-labor intensive industries; this corresponds to the pattern of protection reported for other Latin American countries (see for example Hanson and Harrison (1999) on Mexico).

Brazil gradually liberalized its trade regime from 1988 to 1994. Similarly, Colombia gradually reduced its trade barriers from 1984 to 1994, with the biggest tariff cuts occurring in 1990 and 1991. ${ }^{4}$ These liberalization episodes offer an excellent environment for studying the labor market adjustment to trade reforms for three main reasons. First, the reforms significantly reduced the level of protection. This is evident in Tables $1 \mathrm{a}$ and $1 \mathrm{~b}$ that report average tariff levels during the 1980s and 1990s for Brazil and Colombia, respectively. The average tariff declined from $58.8 \%$ in 1987 to $15.4 \%$ in 1998 in Brazilian manufacturing. Similarly, the average tariff declined from $27 \%$ to $10 \%$ between 1984 and 1998 in Colombia. The declines in tariffs are lower in Colombia than in Brazil, because Brazilian tariff data include only manufacturing, while the Colombian data include non-manufacturing sectors with typically lower tariffs. The bottom panel in table $1 \mathrm{~b}$ shows that the average tariff in manufacturing

\footnotetext{
${ }^{3}$ The source of tariff information for Colombia is the Colombian National Planning Department (DNP). Tariffs are at the 2-digit ISIC level, which matches the level of industry aggregation in the Colombian household data. See Goldberg and Pavcnik (2001) for details about the Colombian tariff data. The source of the Brazilian trade data is Muendler (2002) at http://socrates.berkeley.edu/ meundler/. These data are based on Kume et.al. (2000). The original data provide the tariff levels at the nivel 80 industrial classification. We have aggregated the data to nivel 50 , and made some additional adjustments so that the tariff information corresponds to the level of industry aggregation in the Brazilian labor force data. See Pavcnik, Blom, Goldberg, and Schady (2002) for details about the Brazilian tariff data.

${ }^{4}$ See Pavcnik and Goldberg (2001) and Pavcnik, Blom, Goldberg, and Schady (2002) for details about the exact timing of the reforms.
} 
declined from 50\% in 1984 to $13 \%$ in 1998 in Colombia, suggesting that the tariff declines in manufacturing are similar in Brazil and Colombia. In addition to the drastic tariff reductions, both countries virtually eliminated NTBs. In Colombia, the average coverage ratio declined from $72.2 \%$ in 1986 to $1.1 \%$ in 1992. In our analysis, we focus on tariffs rather than NTBs, since tariffs are the primary trade policy instruments in these countries. We consider the use of tariff data to be a strength of our approach. Tariffs are much easier to measure and, unlike NTBs, comparable over time. ${ }^{5}$ In addition, tariffs are positively correlated with NTBs in both countries over our sample period; hence, it is not the case that tariff declines are matched by increases in less transparent NTBs, as it happened in many developed economies in the 1980's.

A second advantage of focusing on the Brazilian and Colombian trade liberalization episodes is that both countries liberalized tariffs gradually, in the course of multiple trade liberalization rounds; therefore, our data provide (in addition to the cross-sectional variation) ample tariff variation over time that we can exploit for identification.

Third, in addition to drastically lowering the level of protection, the trade reforms also altered the structure of protection across industries in both countries. Figures $1 \mathrm{a}$ and $1 \mathrm{~b}$ plot industry tariffs in 1998 against industry tariffs in 1986 in Brazil and 1984 in Colombia, respectively. The figures show that the dispersion of tariffs was significantly reduced during the reform. The low year-to year correlations of industry tariffs before and after the reform further suggest that the structure of protection has changed. For example, the correlation between industry tariffs in 1986 (the beginning of our sample) and 1992 (the year after the major trade liberalization) in Colombia is .46. Similarly, the correlation between tariffs in 1987 (the year prior to Brazilian trade reform) and 1995 (the year following the reform) is .6 in Brazil. The changes in the structure of protection reflect Brazil's and Colombia's commitment to economywide trade reforms to achieve the low tariffs negotiated with the WTO. This commitment to economy-wide reforms limited the ability of interest groups to affect trade policy changes and translated into bigger tariff declines in industries with traditionally high levels of protection. Finally, these declines in trade protection were also mirrored in an increase in import penetration.

\footnotetext{
${ }^{5}$ Detailed industry information on NTBs is not available for Brazil, and it is available for only 3 years for Colombia. We do not use NTBs for several reasons. First, NTBs are very difficult, if not impossible, to measure. The anecdotal evidence suggests that while statistical agencies collecting NTB data make the data comparable across industries within a year, little effort is spent on making the data consistent across years. This complicates the use of timeseries data on NTBs. Second, in our empirical framework we control for changes in imports, which partially accounts for the effects of changes in NTBs. Finally, unlike in many developed countries, tariffs have always been the main policy instrument in Brazil and Colombia.
} 
Import penetration increased from around $20 \%$ in 1984 to over $30 \%$ in manufacturing in Colombia; in Brazil, it grew from 5.7\% in 1987 to $11.6 \%$ in 1998. It is interesting to note that although trade liberalization almost doubled import penetration in Brazil, Brazilian firms continue to be exposed to significantly lower import penetration than their Colombian counterparts.

\subsection{Labor Force Data}

We link the data on trade exposure to labor force data on individual workers. For Brazil, we use information from the Pesquisa Mensal de Emprego (PME), collected by the Brazilian Statistical Bureau over 12 years, from 1987 to 1998. The data cover the 6 largest metropolitan areas so that our results are representative of the urban labor markets. We focus on individuals in the age range of 15-65, who work full time (defined as working more than 25 hours per week) in manufacturing. Using the survey information, we create several variables that control for worker characteristics such as age, gender, education, geographic location, informal sector of employment, self-employment, industry affiliation, and wage. We match the PME industry codes with tariff codes, which yields 20 manufacturing industries per year and 240 industry-year observations. Our hourly wage measure is created by dividing monthly wage by 4 times the reported number of hours worked in a given week. Based on completed years of education, we classify workers into those with no complete education, complete elementary education, complete lower secondary education, complete secondary education, and complete university education.

Most importantly, the PME contains information on whether a worker has "carta assinada", a signed work card, which enables us to distinguish between workers employed in the formal and informal sectors. In Brazil, workers employed by an employer complying with labor market legislation have the terms of their employment contract written in their work card, "cartiera de trabalho". A worker with a signed work card is entitled to several benefits and rights. Workers without a signed work card are considered to be working in the informal sector. Based on this information, we create an indicator for informality.

For Colombia, we use labor force data from the June waves of the Colombian National Household Survey (NHS), which is administered bi-annually by the Colombian National Statistical Agency (DANE). Our data cover urban areas in the years 1986, 1988, 1990, 1992, 
1994, 1996, and 1998. We construct several variables that control for worker demographics and employment characteristics such as age, gender, marital status, family background, education, literacy, occupation, industry of employment, geographical location, and hourly wage. We also create controls for whether an individual works for a private company, government, or a private household, and whether he/she is an employer or self-employed. Industry codes are reported at the 2-digit ISIC level, yielding 33 industries per year. ${ }^{6}$ Hourly wages are constructed based on the information on the reported earnings and the number of hours worked normally in a week. Based on the information on highest completed grade, we classify workers into those with no complete schooling, complete primary school, complete secondary school, and complete university degree. Furthermore, the June waves of the NHS contain information on whether the worker's employer pays social security taxes. The employer's compliance with the social security legislation (and thus labor market regulation) provides an excellent indicator for whether a worker is employed in the formal sector.

The main disadvantage of our individual worker data is that we do not have information on unionization. This may not be that problematic in the case of Colombia. Edwards (1999) plus anecdotal evidence suggest that unions do not have significant power in most Colombian industries (public sector and the petroleum industry are an exception). Unions may potentially have more power in Brazil where about $37 \%$ of manufacturing workers belong to the union (Arbache and Carneiro (2000)). We address this potential problem in our empirical work.

\section{Labor Market Regulation}

Our theoretical discussion in section 2 suggests that the effects of trade liberalization on informality may depend on the labor market institutions. In this section we briefly describe the labor market reforms undertaken by Brazil and Colombia during our sample period and contrast the labor market flexibility in the two countries.

\footnotetext{
${ }^{6}$ Our tariff data provide information on 21 industries. Some of the industry-year cells contain very few worker observations after we split the sample into formal and informal workers. Therefore, we explore the robustness of our results when we exclude these industries. These industries are forestry (ISIC 12) fishing (13), coal mining (21) metal ore mining (23), other mining (29), and international and other extra-territorial bodies (96).
} 
Let us first focus on Colombia. The Colombian labor market is highly regulated and formal firms face large dismissal costs when they fire a worker for "unjust" reasons. ${ }^{7}$ In order to increase the labor market flexibility, Colombia implemented a labor market reform in 1990 (Law 50 of December 1990). Kugler (1999), Kugler and Cardenas (1999) and Edwards (1999) provide compelling evidence that this reform significantly lowered the cost of firing a worker in several ways. In addition, the reform increased the flexibility of fixed-term contracts and expedited the process of mass layoffs. Overall, these changes are believed to have increased the flexibility of the Colombian labor market. In fact, the empirical work by Kugler (1999) and Kugler and Cardenas (1999) finds that the increased labor market flexibility following the reform induced higher labor market turnover in Colombia. In particular, the reduction in the dismissal cost is associated with a decline in average tenure and an increase in employment exit rates that are larger in the formal sector (that was directly affected by the reform) than in the informal sector (that was not affected by the reform).

Brazil also undertook a labor market reform in 1988. Paes de Barros, Corseuil, and Bahia (2000) describe the changes in detail. In contrast to the Colombian reforms, the Brazilian reforms are believed to have decreased the flexibility of the Brazilian labor market. However, the empirical work on the impact of these reforms on firm turnover by Paes de Barros, Corseuil, and Bahia (2000) finds little robust evidence that the increase in the dismissal costs had a significant impact on employment exit rates.

The differences in the response to the labor market reforms in Brazil and Colombia are not surprising. A study by Heckman and Pages (2000) on labor market regulation in Latin America suggests that the labor market is substantially more regulated in Colombia than in Brazil. In particular, the paper provides evidence that the expected cost of dismissing a worker is much higher in Colombia than in Brazil, even after Colombia's 1990 labor market reform. The expected cost of dismissing a worker was about .9 of the monthly wage in Brazil and about 6.1 monthly wages in Colombia at the end of the 1980s. The expected cost of dismissing a worker amounted to 1.8 monthly salaries in Brazil and 3.5 monthly salaries in Colombia at the end of the 1990s. Given the lower firing costs in Brazil, Brazilian formal firms may have had significant more flexibility in firing relative to their Colombian counterparts before and after the labor

\footnotetext{
${ }^{7}$ According to Kugler and Cardenas (1999), the only cases in which employers did not have to pay dismissal costs were when employees were fired "because of undue care, sabotage, or release of the employers' proprietary information (page 7)".
} 
reform. Hence we would expect the effects of trade policy on informality to vary across the two countries; moreover, the effects may also differ depending on whether we focus on the pre-, or post-labor-reform period in Colombia. We explore these differences in our empirical work in section 6.

\section{Informality and trade: Some preliminary evidence}

Our distinction between a formal and informal sector in Brazil and Colombia is based on compliance with labor market regulation. Since the selection of workers into the informal sector is obviously not random, we first check how worker characteristics differ across the two sectors. Table 2 summarizes worker characteristics in the formal and informal sectors for Colombia in $1994 .^{8}$ Informal workers are more likely to be male, older, less educated, and illiterate. Furthermore, informal workers are also more likely to be single, albeit more likely to be head of the household. ${ }^{9}$ These differences in the demographic composition of the labor force across the informal and formal sectors highlight the importance of controlling for individual worker characteristics in our empirical analysis rather than relying on industry data.

Informal and formal workers also differ in their job characteristics. In particular, it is often claimed that informal jobs are associated with lower job quality. This claim, controversial as it is, is of particular interest to those studying the effects of trade on inequality. If trade liberalization induces a shift to the informal sector, and if this sector offers "worse" jobs, then trade would have contributed to inequality, whereas inequality is here broadly defined as the difference between those with "good" and those with "bad" jobs.

We can get a rough idea about the job characteristics in the informal sector by analyzing information from the 1994 June wave of the Colombian National Household Survey. In this year, the survey contains a special module on the Quality of Employment. In particular, the survey provides information on how workers view the workplace conditions, job characteristics, and employee relations. For each of these questions, we create an indicator that is one if the respondent evaluates the conditions as excellent or good, and 0 if the worker evaluates the

\footnotetext{
${ }^{8}$ We focus our discussion on 1994 because the 1994 survey contains a special module on the quality of employment. Descriptive statistics on worker demographics for other years yield similar findings, except that in some years informal workers appear to be younger than formal workers (although the age differences are in all cases very small). In Brazil, informal workers are also less educated and more likely to be men, but they are younger than their informal counterparts.

${ }^{9}$ This second finding is a bit surprising. Our regression results later reveal that conditional on other characteristics, head of the households are less likely to be informal workers.
} 
conditions as average or bad. In addition, workers also provide information on whether they receive benefits and job training.

Table 2 provides survey means of the job characteristics of formal and informal workers. The overall impression is that work in the informal sector is considered less satisfying. Several differences between the responses of formal and informal workers are worth noting. First, formal workers are more likely to be satisfied with the job characteristics, workplace conditions, and employee relations. Second, formal jobs are associated with significantly more benefits than informal positions. In particular, formal workers are much more likely than informal workers to receive individual benefits such as health coverage, dental coverage, vacations, incentive bonuses, maternity leave, unemployment benefits and pensions, sick leave, transportation benefits, insurance, and family subsidy. Overall, $83 \%$ of informal workers report receiving no benefits through their job - this number is only $4 \%$ for formal workers. Formal workers are also more likely to receive on the job training than informal workers. Finally, informal jobs are associated with a higher degree of uncertainty about employment duration.

Informal workers are more likely to hold temporary positions than formal workers. This, however, could be considered a benefit of informality, reflecting the flexibility of informal labor market arrangements. Table 2 reveals that the two groups do no differ much in the average normal hours worked in a given week, though the variance of hours worked is bigger in the informal sector. In addition, while there is no difference in average hours worked across the formal and informal sectors for men (average hours worked is 50.6 and 50.9 respectively), women in the informal sector work on average 2 hours less per week than women in the formal sector (46.2 and 44.3, respectively). Lower average hours for women in the informal sector, and higher dispersion of hours worked for all informal workers, indicate that the informal sector provides a more flexible arrangement. Overall, this descriptive evidence suggests that informality is associated with lower job and workplace satisfaction, very few benefits, lower incidence of job training, and higher uncertainty about duration of employment. However, informality is also associated with more flexibility in the job arrangement.

We next turn to the question of whether trade liberalization has contributed to the incidence of informal employment in Brazil and Colombia. Tables $3 \mathrm{a}$ and $3 \mathrm{~b}$ report the aggregate shares of informal workers during our sample for the two countries. The incidence of informal employment increased from .1 in 1987 to .2 in 1998 in Brazilian manufacturing 
industries. The aggregate share of informal workers does not increase over time in Colombia. ${ }^{10}$ However, given that different sectors were exposed to differential trade shocks, aggregate data could potentially mask industry level changes.

In addition, the tables suggest that the probability of informal employment is higher in Colombia than in Brazil. However, the Colombian figures also include the non-manufacturing sectors with higher shares of informal workers. Column 2 of table $3 \mathrm{~b}$ reports the aggregate share of informal workers in manufacturing sectors for Colombia. These figures confirm that informality is more widespread in Colombia than in Brazil. Overall, $48 \%$ of all manufacturing workers work in the informal sector. Moreover, the share of informal workers has increased over time also in Colombian manufacturing. The difference in the share of informal workers in Brazil and Colombia is not surprising. Kugler's (1999) model predicts that the lower the cost of dismissing a worker, the higher the compliance with labor market legislation (in other words, the higher the share of the formal sector). Since Colombian firms face a more rigid labor market and higher cost of dismissing a worker than Brazilian firms they less incentive to comply with labor market regulation.

Naturally, the question arises whether these changes in informality stem from changes in the composition of industry employment (i.e., trade liberalization may have expanded the employment in industries that employ a proportionally larger share of informal workers) or from within industry changes in informal employment (i.e., within an industry, workers move from formal to informal jobs). Several pieces of evidence suggest that the within industry movements from formal to informal jobs dominate. To begin with, in our previous work on Colombia and Brazil (see Attanasio, Goldberg, and Pavcnik (2002) and Pavcnik, Blom, Goldberg, and Schady (2002)) we found that industry shares in total employment do not vary much over time during our sample period. If trade policy changes had led to reallocation of resources across industries, we would expect low year-to-year correlations of industry shares in total employment. However, the correlation between the 1986 and 1998 shares is .99 in Colombia, while in Brazil the correlation between the 1987 and 1998 shares is .96. Moreover, if most of the increase in informality stemmed from changes in the composition of employment across industries with

\footnotetext{
${ }^{10}$ The data suggest that the aggregate informality share is lower in 1994 than in other years. This is a bit puzzling. The comparison of the means of other worker characteristics for 1994 and other years suggests that the 1994 data have similar means of other worker characteristics as the 1992 and 1996 survey (see table 1d in Goldberg and Pavcnik (2001)). Moreover, the means of the characteristics of the formal and informal workers in 1994 are not very different from those in other years.
} 
different informality intensities, we would expect a large positive correlation between changes in the industry shares in total employment and industry informality intensity. However, regressing the change in the industry share in total employment between 1998 and 1987 on the share of informal workers in industry employment in $1987^{11}$ does not reveal such a strong positive correlation. The coefficient of the share of informal workers is .047 (p-value .07) in Brazil, and .004 (p-value .33) in Colombia.

Most importantly, a decomposition of the change in the share of the informal workers into changes that occurred within industries and the changes that occurred across industries indicates that most of the increase in informality stems from movements of workers from formal to informal jobs within industries. In particular, we decompose the change in the share of informal workers in total employment between 1998 and 1987 (1986 in Colombia) $\Delta I$ into within and between industry shifts, respectively: $\Delta I_{t}=I_{t}-I_{\tau}=\sum_{j} \Delta i_{j t} E_{j .}+\sum_{j} \Delta E_{j t} i_{j .}$, where $E_{j t}$ is the share of industry $j^{\prime}$ 's employment in total employment at time $t, i_{j t}$ is the share of informal workers in total employment in industry $j, E_{j .}=.5\left(E_{j t}+E_{j \tau}\right)$, and $i_{j .}=.5\left(i_{j t}+i_{j \tau}\right) .{ }^{12}$ Table $3 \mathrm{c}$ presents the results. $88 \%$ of the increase in the informal employment in Brazil stems from movement of workers from formal to informal jobs within industries. In Colombia, withinindustry movements of workers account for almost all of the increase in the informal employment. In fact, the negative sign on the between-industry shift suggests that the small shifts in the employment across industries would actually lead to a decline in informal employment. In sum, the evidence indicates that the mobility of workers across the formal and informal sectors within an industry is greater than the mobility of workers across industries. ${ }^{13}$ As a result, our empirical work in the next section focuses on explaining whether trade liberalization is associated with these within industry shifts in informality.

This preliminary evidence suggests that if trade policy had any effects on the incidence of informal work in Brazil and Colombia at all, such effects would have operated through changes

\footnotetext{
${ }^{11}$ In Colombia, we use 1986, the first year of our sample.

12 This decomposition has been often used in the literature on skill-upgrading to decompose the change in the share of skilled workers between and within industries.

${ }^{13}$ Obviously, given that we do not have very disaggregated industry data (especially in the case of Colombia), some of the movements within industries could actually represent changes in composition of employment across more detailed industry categories. In fact, in Brazil where industry classification is more detailed, movements across industries do account for a larger share of the informality increase than in Colombia. However, the within industry movements continue to dominate.
} 
in the composition of formal and informal sectors within industries. However, many other factors such as labor market reforms and macroeconomic conditions may be influencing the aggregate trends. In the next section, we rely on detailed micro level data on worker characteristics and industry panel data on tariffs to study the association between tariffs and informality more formally.

\section{Informal employment and trade policy}

\subsection{Empirical Methodology}

We relate trade policy to the probability of working in the informal sector by employing a two-step estimation approach that has been used in the labor literature on wage premia. In the first stage, we use a linear probability model and regress the indicator $\mathrm{Y}_{\mathrm{ijt}}$ for whether a worker $\mathrm{i}$ employed in industry $\mathrm{j}$ at time $\mathrm{t}$ works in the informal sector on a vector of worker characteristics $\mathrm{H}_{\mathrm{ijt}}$, such as age, age squared, education indicators, gender, geographic location, and a set of industry indicators $\mathrm{I}_{\mathrm{ijt}}$ indicating worker i's industry affiliation:

$$
Y_{i j t}=H_{i j t} \beta_{H t}+I_{i j t} * i p_{j t}+\varepsilon_{i j t}
$$

The coefficient on the industry dummy $\mathrm{ip}_{\mathrm{j}}$ captures the part of the variation in informal employment that cannot be explained by worker characteristics, but can be explained by workers' industry affiliation. We call these coefficients industry informality differentials. ${ }^{14}$ We express the estimated informality differentials as deviations from the employment-weighted average informality differential $\left(\mathrm{ip}_{\mathrm{j}}\right) .{ }^{15}$ This normalized informality differential can be interpreted as the percentage point difference in probability of informal employment for a worker in a given industry relative to an average worker in all industries with the same observable characteristics. The normalized informality differentials and their standard errors are calculated using the Haisken-DeNew and Schmidt (1997) two-step restricted least squares procedure provided to us by John P. Haisken-DeNew and Christoph M. Schmidt. ${ }^{16}$ The first stage

\footnotetext{
${ }^{14}$ In addition to the linear probability model, we have computed industry informality differentials using a probit. The two specifications yield similar marginal industry effects. The correlation between industry informality differentials based on the linear probability model and the probit is over .8 for Brazil and Colombia. We thus continue to use the linear probability model.

${ }^{15}$ The sum of the employment weighted normalized informality differentials is zero.

${ }^{16}$ Haisken DeNew and Schmidt (1997) adjust the variance covariance matrix of the normalized industry indicators to yield an exact standard error for the normalized coefficients. The adjustment of the variance covariance matrix occurs by taking into account the linear restriction that the employment-share weighted sum of the normalized coefficients is zero.
} 
regressions are estimated separately for each year in our sample. In the second stage, we pool the industry informality differentials $\mathrm{ip}_{\mathrm{j}}$ over time and regress them on trade related industry characteristics:

$$
i p_{j t}=T_{j t} \beta_{T}+D_{j t} \beta_{D}+u_{j t}
$$

where Tjt is a vector of trade exposure measures such as tariffs, imports, and exports and $\mathrm{D}_{\mathrm{jt}}$ is a vector of industry and time indicators. Because our dependent variable in the second stage is estimated, we estimate (9) with weighted least squares (WLS), using the inverse of the variance of the informality estimates from the first stage as weights. This puts more weight on industries with smaller variance in informality differentials. We also account for general forms of heteroskedasticity and serial correlation in the error term in (9) by computing robust (HuberWhite) standard errors clustered by industry.

\subsection{First Stage Results}

Prior to discussing the relationship between trade policy and the probability of working in the informal sector, we provide some information on the first stage results. Tables $4 \mathrm{a}$ and $4 \mathrm{~b}$ report the coefficients on the individual characteristics that are associated with working in the informal sector in selected years for Brazil and Colombia, respectively. The results suggest that younger workers are more likely to work in the informal sector. In Colombia, women and the more educated workers are less likely to work in the informal sector. In Brazil, we also persistently find that workers with complete university degree are less likely to work in the informal sector, but the coefficients on the complete elementary, lower secondary, and secondary education are usually statistically insignificant. Moreover, unlike in Colombia, women are more likely to participate in informal work. In Colombia, we also control for household characteristics that may affect a person's propensity to work in the informal sector such as whether a person is married, head of the household, the number of children in a household aged 0-4, number of inactive adults in a household, and earnings of other household members. The results in table $4 \mathrm{~b}$ suggest that married individuals and household heads are more likely to work in the formal sector. Moreover, workers living in households with children aged 0-4 are more likely to work in the informal sector (albeit the coefficient is not always significant). Surprisingly, the coefficient on the interaction of a female indicator with the number of children is insignificant. 
Finally, workers living in households with higher income of other household members are less likely to work in the informal sector.

Second, in both Brazil and Colombia, industry indicators in the first stage are always jointly statistically significant, and most of them are also individually statistically different from zero. This suggests that even conditional on worker characteristics, industry affiliation is an important determinant of the probability of working in the informal sector. In particular, in Brazil, workers employed in clothing, manufacture of wood and wood products, and oil extraction are more likely to be employed in the informal sector than workers with the same observable characteristics in other industries. In Colombia, workers are more likely to work in the informal sector if they are employed in the manufacture of wood and wood products, agriculture, restaurants and hotels, and household services. Finally, the industry informality differentials are highly correlated over time in Brazil. Almost all year-to-year correlations are above .9. For example, the correlation between 1987 and 1988 industry informality differentials is .98 and the correlation between 1987 and 1995 informality differentials is .96 (1995 is the year following the end of trade liberalization in Brazil). However, the year-to-year correlations between informality differentials are lower in Colombia, ranging from .6 to $.95 .{ }^{17}$ For example, the correlation between 1986 and 1990 informality differentials is .92. However, the correlation between 1986, the first year of our sample and 1994, the year that follows the period of dramatic trade liberalizations is .71. High year-to-year correlations of industry informality differentials in Brazil suggest that trade policy changes are unlikely to be associated with changes in the informal employment. However, the lower correlation coefficients in informality differentials in Colombia suggest that trade policy could at least in principle affect the incidence of informal employment in this country.

\subsection{Second Stage Results: Industry Informality Differentials and Trade Policy}

In the second stage, we relate industry informality differentials to trade policy (tariffs in particular) as suggested in equation (9). ${ }^{18}$ Note that controlling for individual worker characteristics in the first stage eliminates some of the potential estimation biases in the

\footnotetext{
${ }^{17}$ Correlations for Colombia are based on computations that exclude industries with few observations. Those industries have very noisy measures of industry informality differentials and thus make these correlations even lower.

${ }^{18}$ A $20 \%$ tariff is denoted in our data as .2.
} 
relationship between informality and tariffs stemming from differences in worker composition across industries. For example, if industries with a higher share of unskilled workers receive higher trade protection and unskilled workers are more likely to work in the informal sector, reliance on industry level data could potentially yield a spurious positive relationship between informality and trade policy. Since we control for worker characteristics in the first stage (and thus control for industry composition each year), our second stage results are not driven by differences in worker composition across sectors. Moreover, all second stage regressions include industry fixed effects and year indicators. Inclusion of these controls additionally reduces the potential estimation biases. For example, business cycle fluctuations might independently impact tariff formation and the probability of informal employment. If government raises tariffs during recessions and workers move from the formal to the informal sector, the tariff coefficient could be biased upward. Similarly, to the extent that labor market reforms of 1988 in Brazil and 1990 in Colombia had similar affects across all industries (conditional on controlling for industry composition in the first stage), year indicators capture their effects. Finally, industry fixed effects control for unobserved industry characteristics that are time-invariant. Such controls are important, since unobserved industry attributes, such as an industry's ability to form a lobby, industry productivity, or capital intensity may simultaneously affect industry tariff formation and industry informal employment. For example, less productive industries may be more effective at lobbying the government for higher tariffs and also employ relatively more informal workers.

The results for Brazil are reported in Table 5a. The table reports the coefficients on each independent variable and p-values associated with the coefficients. Column 1 reports the results from the regression of industry informality differentials on tariffs, industry indicators, and year indicators. The coefficient on tariff in column 1 is small in magnitude and insignificantly different from zero. This suggests that there is no statistical relationship between tariffs and probability of working in the informal sector. Although tariffs are our preferred way of measuring an industry's exposure to trade because they capture the direct effect of policy on informality, we also experiment with other measure of exposure to trade (such as imports and exports) commonly used in trade studies. The use of these variables is not motivated by trade theory, and we consider these regressions mostly as a robustness check on our estimates of the tariff coefficients. In particular, in column 2, we add lagged import penetration and lagged 
export orientation as regressors. ${ }^{19}$ The inclusion of additional regressors does not change the magnitude or the significance of the tariff coefficient. Moreover, the coefficient on import penetration is insignificant. However, the coefficient on export orientation is positive and significant.

Trade reforms in Brazil were accompanied by significant exchange rate fluctuations. These currency fluctuations could differentially impact employment in traded and non-traded sectors. For example, an exchange rate appreciation is likely to lead to an expansion of the nontradable sector, which in general employs a higher share of informal workers (though this effect is less relevant in our Brazilian data, which contain only manufacturing industries). Note however, that if exchange rate fluctuations were driving our results, we would expect most of the increase in aggregate informality to stem from reallocation of employment across industries. Yet, the results reported in section 5 suggest that most of the changes in aggregate informality are due to within industry changes. Accordingly, the focus in our empirical work is on investigating whether these within industry changes in informality are associated with variation in industry tariffs. Nevertheless, to be confident that our results are robust to controlling for exchange rate fluctuations we also estimate a specification in which we interact lagged import penetration and lagged export orientation with the exchange rate. ${ }^{20}$ The results are reported in column 3 of Table 5a. The inclusion of the exchange rate interaction does not affect either the magnitude or the significance of the tariff coefficient. ${ }^{21}$ Finally, in columns 4, 5, and 6 we also estimate the relationship in first differences and obtain no significant relationship between trade reform and probability of informal employment for Brazil.

The above analysis suffers from three potential problems. First, the 1988 labor reform may have affected the relationship between trade policy and informality. Unfortunately, we do not have sufficient data prior to the labor reform to explore whether the relationship between trade policy and informality has changed after the reform. However, our prior is that this is not a big issue. Heckman and Pages (2000) suggest that the labor market in Brazil was substantially less regulated than in Colombia. In addition, we find that year-to-year correlations of industry

\footnotetext{
${ }^{19} \mathrm{We}$ use lagged values because trade flows are a function of factor prices. Of course, to the extent that trade flows are serially correlated, our approach does not fully eliminate the simultaneity bias.

${ }^{20} \mathrm{We}$ use the nominal exchange rate (real/\$US) from Muendler (2002). We do not use the nominal effective exchange rate from IMF because it is only available since 1992.

${ }^{21}$ Note that the year effects already control for the economy-wide effect of exchange rates (that does not vary across industries). The interaction terms are meant to capture the possibility that exchange rate fluctuations have different effects depending on a sector's import or export orientation.
} 
informality differentials are extremely high, and that the differentials are very similar in magnitude before and after the 1988 labor reform. This limits the scope for important interactions of labor market with trade reforms. Nevertheless, to be sure, we also repeat our previous analysis using only the years in our sample after the labor market reform (i.e., from 1989 onwards). The results are reported in Table 5b, in the same order as the results in Table 5a, and lead to the same conclusions.

The second potential problem with our analysis is that we cannot control for union membership in the first stage of our estimation. If industry union power affects both the probability of informal employment and tariff formation, our results could be biased. To the extent that union power in each industry has not changed over time in Brazil, industry fixed effects would capture union effects. This may in fact be a realistic assumption. Arbache and Carneiro (2000) report the shares of unionized workers in various manufacturing industries in 1992 and 1995, and show that the shares are relatively stable over time. ${ }^{22}$

Finally, the lack of significant relationship between the changes in informal employment and contemporaneous tariff changes might not be surprising if firms respond to trade reform with a lag. In order to explore this possibility, we estimate specifications in which we use one-year lagged tariffs (and tariff changes) rather than the contemporaneous tariffs (and tariff changes) as the explanatory variable. The results are presented in Table $5 \mathrm{c}$ in the same order as the results in Table 5a. We continue to find no association between tariff changes and changes in the share of informal employment. In sum, our analysis suggests no relationship between trade reform and the incidence of informal employment in Brazil. ${ }^{23}$

Table 6a presents the results for Colombia. The tariff coefficient in column 1 is negative and significant, which suggests that tariff declines are associated with increases in informal employment. In particular, a 1-percentage point decline in a tariff in a given industry is

\footnotetext{
${ }^{22}$ They use data from PNAD. During the trade liberalization of the early 1990s, these data are only available for 1991 and 1994; the surveys for 1989 and 1990 do not contain information on union status.

${ }^{23}$ In unreported regressions, we have also estimated the relationship between probability of informal employment and tariffs by pooling worker level data over all years and including tariffs and year indicators directly in the first stage in equation 8 . We adjusted standard errors to reflect that tariffs vary over time and across industries only. As expected, we continue to find no association between tariffs and probability of informal employment, as in our twostage approach. Note, however, that the one-stage estimation does not allow us to explore the relationship between informality and tariffs in first differences because we do not have repeated observations on the same individual across years. In these one-stage regressions, we have also allowed the effect of tariffs to vary across skilled and unskilled workers (where skilled workers are defined as those with complete secondary or university education). We find some suggestive evidence that relative to skilled workers, declines in tariffs are associated with increased probability of informal employment for unskilled workers.
} 
associated with a .1 percentage point (i.e. .001) increase in the probability of informal employment. This would translate into a 4-percentage point increase in the probability of informal employment in an industry that experienced a 40-percentage point decline in tariffs. These effects seem relatively small in magnitude. In column 2, we add lagged imports and exports as our regressors. ${ }^{24}$ The addition of these controls barely changes the magnitude of the tariff coefficient, but the coefficient is now less precisely estimated. Moreover, the positive and significant coefficient on imports suggests that increased import competition is associated with higher probability of informal employment, while increases in industry export orientation are associated with declines in probability of informal employment. As in Brazil, the Colombian trade reforms were accompanied by large exchange rate fluctuations. But just as in Brazil, most of the increase in informality in Colombia can be attributed to within industry changes rather than reallocation across industries. We do not believe that exchange rate fluctuations are driving the association between within industry changes in informality and changes in industry tariffs. Nevertheless, we formally check the robustness of our tariff coefficient by estimating a specification in which we interact lagged imports and exports with the exchange rate. ${ }^{25}$ The results are presented in column 3. The inclusion of the exchange rate interactions hardly changes the coefficient on tariffs. Finally, we also estimate the relationship between informality and trade policy in first differences. The results are reported in columns 4, 5 and 6 . The results on tariffs are not robust to first differencing: the coefficients on tariffs are no longer statistically different from zero. However, the results for imports and exports are robust.

The next three tables report several robustness checks. As pointed out in section 3.2, some of the industry-informality-year cells do not contain many observations. In Table $6 \mathrm{~b}$, we repeat our analysis excluding industries with very few workers (see data description on which industries are excluded). This yields similar results to those obtained in Table 6a. Moreover, given that the incidence of informality was unusually small in 1994, we have also repeated our analysis without 1994. These results are reported in Table $6 \mathrm{c}$ and yield similar findings as Table 6a. Finally, as in the case of Brazil, we check whether it takes time for firms to adjust informal employment to trade reform by exploring the relationship between informality and lagged

\footnotetext{
${ }^{24}$ Unlike in Brazil, we cannot use import penetration and export orientation measures because we do not have output data for non-manufacturing industries.

${ }^{25}$ The exchange rate we use is the nominal effective exchange rate from the IMF.
} 
tariffs. $^{26}$ The results are reported in Table $6 \mathrm{~d}$ in the same order as in Table $6 \mathrm{a}$. All the coefficients are well within the $95 \%$ confidence interval of the coefficients on contemporaneous tariffs reported in Table $6 \mathrm{a}^{27}$

We next turn our attention to the labor reform. As discussed in section 4, Colombia underwent a large labor market reform in 1990. This reform significantly reduced the cost of firing a worker and increased the labor market turnover. As a result, the reform may have affected the relationship between trade policy and informality. The model in section 2 suggests that high firing costs make monitoring of formal workers extremely costly, so that the probability of establishing shirking is low. Reducing firing costs effectively increases the probability of detecting and responding to shirking. This in turn implies that the response of the informal sector to trade liberalization will be less pronounced if the trade reform is accompanied by changes in the labor market regulation that decrease firing costs (see also the discussion in section $2 \mathrm{~d}$ ). To explore this possibility, we allow the relationship between tariffs and informality to vary across the pre- and post-1990 reform years; in particular, we interact tariffs with an indicator that is 1 after the 1990 labor market reform, and zero otherwise. The results are presented in table 7.

Two interesting results emerge. First, the coefficient on tariffs is negative in all columns. This suggests that a tariff decline in an industry is associated with an increase in the probability of informal employment prior to the labor reform, when the costs of firing formal workers were high. Moreover, the coefficient on the interaction of tariff with the labor market reform indicator is always positive. This suggests that a tariff decline in an industry is associated with a smaller increase (and potentially an overall decrease) in the probability of informal employment after the reform. The bottom of the table reports the p-value from the test that there is no statistical association between tariffs and informality after the labor market reform. We either fail to reject

\footnotetext{
${ }^{26}$ Because of data availability, we use two-year lags in tariffs.

${ }^{27}$ As in the case of Brazil, in unreported regressions we have also estimated the relationship between probability of informal employment and tariffs by pooling worker level data over all years and including tariffs and year indicators directly into first stage equation 8. As expected, this yielded similar findings to our two-stage estimation results. Note that we cannot estimate this specification in first differences because we do not observe the same individuals over time. Moreover, in some of these specifications, we also allowed the coefficient on tariffs to differ across skilled and unskilled workers (where skilled workers are defined as those with complete secondary or university degree). We found that tariffs do not impact the probability of informal employment differentially across the two groups.
} 
the hypothesis (columns 1, 3, 5, and 6), or find a small, positive relationship between tariffs and informality after the labor market reform (column 2 and 4).

To summarize, we find no relationship between tariff declines and increases in informal employment in Brazil, while this relationship is estimated to be positive, but small, in Colombia prior to labor market reforms. The differences between the findings for Brazil and Colombia, as well as the differences between the pre- and post-labor-reform Colombia, are indicative of the importance of labor market institutions, and can be interpreted within our model. The model suggests that the response of informality to trade liberalization depends on the likelihood of catching and firing shirkers, which in turn is affected by labor market legislation. Since Colombia is more regulated than Brazil, and pre-reform Colombia in particular had the highest firing costs in our sample, our findings are consistent with the theoretical predictions.

\section{Conclusions}

This paper has investigated the relationship between trade policy and the informal sector. Our empirical work does not find significant evidence that the trade reforms contributed to increases in informal employment in Brazil and Colombia. For Brazil, in particular, we find no relationship between trade liberalization and informality. For Colombia, we find that tariff declines are associated with an increase in informal employment in the industries with the largest tariff cuts, but only in the period before the labor market reform. Even in this case, the magnitude of the effect is small. These results suggest that compared to labor market rigidities, trade policy is of secondary importance in determining the incidence of informal employment.

Our work points to the significance of labor market institutions when studying the effects of trade reforms. The differences in the relationship between informality and trade policy between Colombia and Brazil, and the differences in the response in Colombia before and after the labor market reform indicate that labor market institutions play an important role in how trade reform affects informal employment. Firms are more likely to respond to increased exposure to foreign competition through reductions in formal employment, when they operate in rigid labor markets. A similar conclusion is reached by Aghion, Burgess, and Redding (2002), in a study of the impact of trade reforms on growth of Indian states subject to different labor market regulation. Given that many Latin American countries underwent large trade liberalizations during the 1980s and 1990s, and that labor markets in these economies exhibit different degrees 
of flexibility, studying the interaction of labor and trade reforms in these economies remains a fruitful topic for future research.

\section{References}

Aghion, P., R. Burgess, and S. Redding (2002): “Liberalisation, Institutions, and Industrial Performance: Evidence from India" mimeo.

Arbache, J.S. and F.G. Carneiro (1999): "Unions and Interindustry Wage Differentials", World Development 27, pp. 1875-1883.

Attanasio, O., Goldberg P., and N. Pavcnik (2002): "Trade Reforms and Income Inequality in Colombia," mimeo.

Bulow, J. and L. Summers (1986): “A theory of dual labor markets with application to industrial policy, discrimination, and Keynesian unemployment" Journal of Labor Economics, Vol. 4:1, pp. 376-414.

Currie, J. and A. Harrison (1997): "Trade Reform and Labor Market Adjustment in Morocco" Journal of Labor Economics, Vol. 15, pp. S44-71.

Edwards, S. (1999): The Political Economy of Incomplete Market-Oriented Reform: The Case of Colombia. Forthcoming.

Goldberg, P. and N. Pavcnik (2001): “Trade, Wages and the Political Economy of Trade Protection: Evidence from the Colombian Trade Reforms", mimeo.

Haisken-DeNew, J.P. and C.M. Schmidt (1997): "Inter-Industry and Inter-Region Wage Differentials: Mechanics and Interpretation", Review of Economics and Statistics, Vol. 79, No. 3, pp. 516-521.

Hanson, G. and A. Harrison (1999): "Who gains from trade reform? Some remaining puzzles", Journal of Development Economics, Vol. 59, pp. 125-154.

Harrison, A. and E. Leamer (1997): "Labor markets in developing countries: An agenda for research", Journal of Labor Economics, Vol. 15, pp. S1-19.

Heckman J. and Pages C. (2000): “The Cost of Job Security Regulation: Evidence from Latin American Labor Market," NBER Working Paper 7773.

Krueger, A.B. and L.H. Summers (1988): "Efficiency Wages and the Inter-Industry Wage Structure", Econometrica, Vol. 56, pp. 259-293.

Kugler, A. (1999): “The Impact of Firing Costs on Turnover and Unemployment: Evidence from The Colombian Labour Market Reform", International Tax and Public Finance Journal, Vol. 6, no. 3, pp. 389-410. 
Kugler, A. and M. Cardenas (1999): “The Incidence of Job Security Regulation on Labor Market Flexibility and Compliance in Colombia, mimeo.

Kume, H. (2000): “A politica brasileira de importação no period 1987 descrição e avaliação."

Kume, H, Piani, G. And C.F. Souza (2000): "Instrumentos de Politica Comercial no Periodo 1987-1998," mimeo.

Muendler, M. A. (2002): "Trade, Technology, and Productivity: A Study of Brazilian Manufacturers, 1986-1998", University of California, Berkeley mimeo.

Paes de Barros R., C.H. Corseuil, and M. Bahia (2000): "Labor Market Regulations and the Duration of Employment in Brazil," IPEA mimeo.

Pavcnik, N., A Blom, P. Goldberg, N. Schady (2002): “Trade Liberalization and Labor Market Adjustment in Brazil," mimeo.

Saint-Paul, Gilles (1996): Dual Labor Markets: A Macroeconomic Perspective, MIT Press.

Shapiro, C. and J. Stiglitz (1984): "Equilibrium unemployment as a worker discipline device" American Economic Review, Vol. 74, pp. 433-444.

Stallings, B. and Wilson Peres (2000): Growth, Employment and Equity. The Impact of the Economic Reforms in Latin American and Caribbean. Economic Commission for Latin American and Caribbean, Brookings Institution Press, Washington, DC. 
Figure 1a-Tariffs in 1986 and 1998 in Brazil

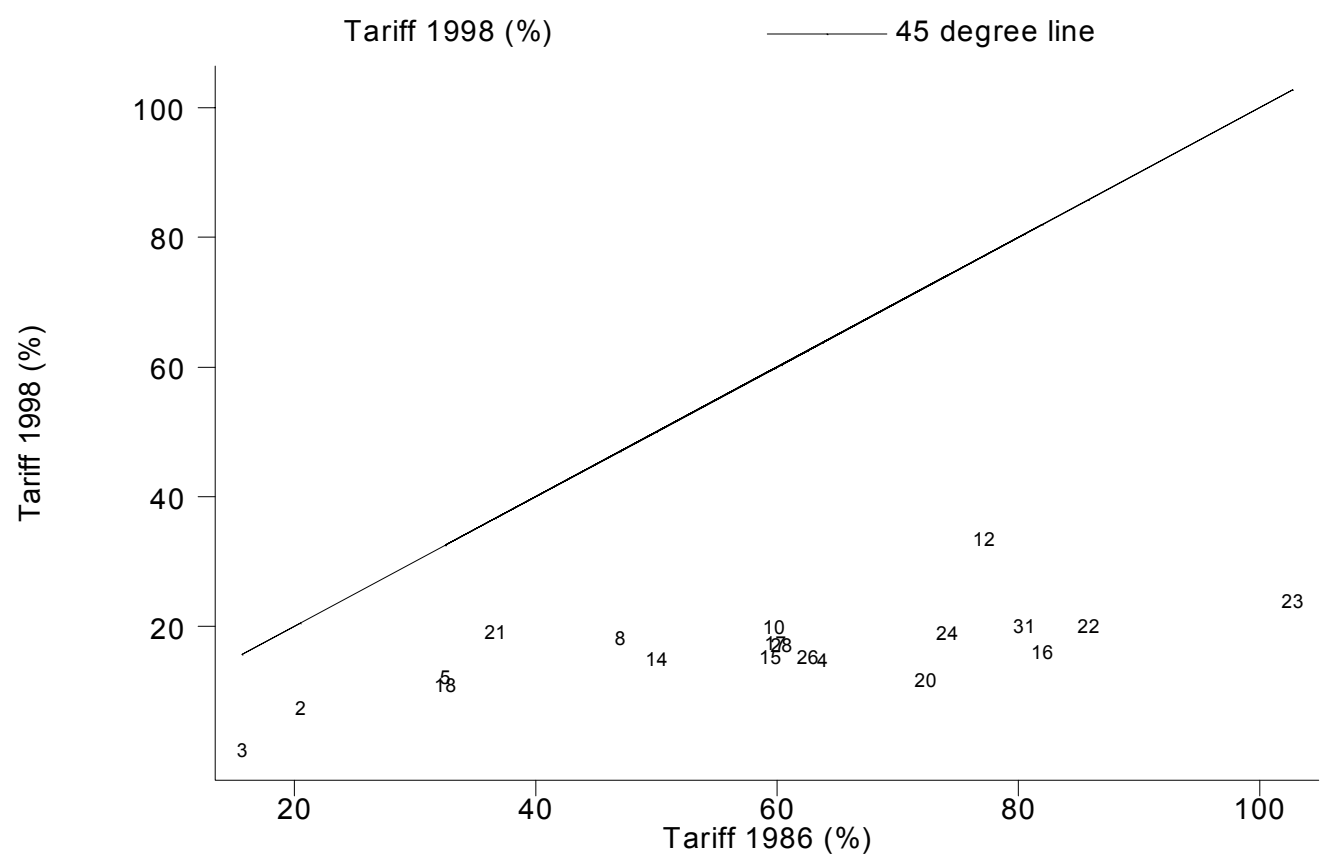

Figure 1b-Industry Tariffs in 1984 and 1998 in Colombia

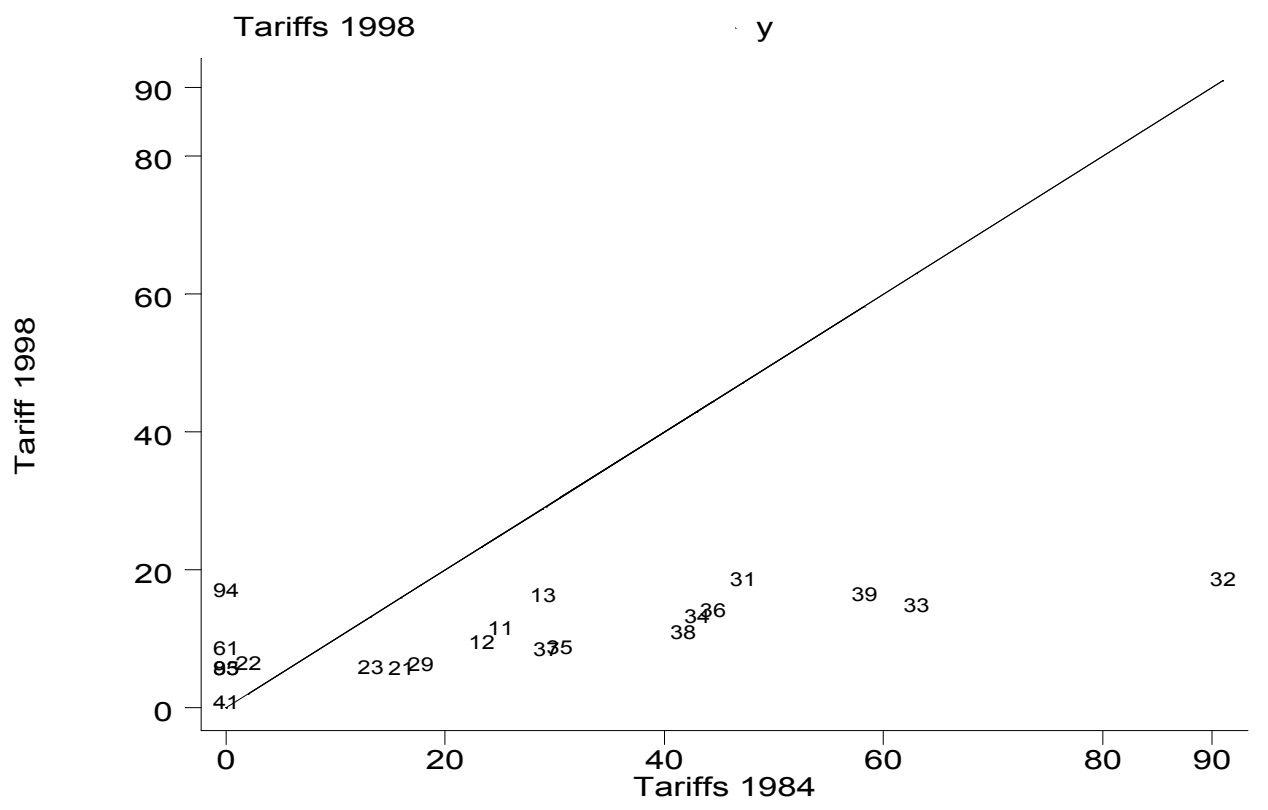

Note: The line is 45 degree line. The numbers are industry symbols (they do not match across the two countries). 
Table 1a--Manufacturing Tariffs in Brazil 1987-1998

\begin{tabular}{lrr}
\hline \hline Year & Mean & S.D. \\
& & \\
1987 & 58.8 & 22.8 \\
1988 & 50.1 & 18.3 \\
1989 & 39.1 & 16.4 \\
1990 & 34.1 & 17.0 \\
1991 & 25.2 & 13.3 \\
1992 & 19.1 & 10.3 \\
1993 & 14.4 & 7.2 \\
1994 & 12.9 & 6.2 \\
1995 & 10.9 & 5.7 \\
1996 & 12.5 & 6.6 \\
1997 & 12.8 & 7.0 \\
1998 & 15.4 & 6.5 \\
\hline \hline Note: There are 20 industries in each \\
year.
\end{tabular}


Table 1b--Tariffs in Colombia 1984-1998

\begin{tabular}{ccrr}
\hline \hline Year & N & Mean & S.D. \\
All Industries & & & \\
1984 & 21 & 27.4 & 24.8 \\
1985 & 21 & 22.2 & 16.7 \\
1988 & 21 & 20.7 & 16.0 \\
1990 & 21 & 17.5 & 14.0 \\
1992 & 21 & 10.6 & 4.1 \\
1994 & 21 & 9.7 & 4.8 \\
1996 & 21 & 9.8 & 5.1 \\
1998 & 21 & 9.9 & 5.1 \\
Manufacturing & & & \\
1984 & 9 & 49.8 & 19.0 \\
1985 & 9 & 36.6 & 9.5 \\
1988 & 9 & 33.5 & 11.1 \\
1990 & 9 & 29.1 & 9.1 \\
1992 & 9 & 12.9 & 3.4 \\
1994 & 9 & 12.9 & 3.6 \\
1996 & 9 & 13.0 & 3.9 \\
1998 & 9 & 13.1 & 3.8 \\
\hline \hline
\end{tabular}

Note: There are 21 industries overall and 9 manufacturing industries. Source: Authors' calculations based on tariff data provided by DNP. 
Table 2--Informal and Formal Workers Colombia 1994

\begin{tabular}{|c|c|c|}
\hline & Informal & Formal \\
\hline \multicolumn{3}{|l|}{ Individual Characteristics } \\
\hline Hourly wage & 1577.2 & 1660.3 \\
\hline Male & 0.613 & 0.567 \\
\hline Age & 35.5 & 33.8 \\
\hline Literate & 0.975 & 0.996 \\
\hline No complete schooling & 0.174 & 0.065 \\
\hline Elementary school complete & 0.536 & 0.389 \\
\hline Secondary school complete & 0.217 & 0.397 \\
\hline University complete & 0.073 & 0.148 \\
\hline Married & 0.330 & 0.386 \\
\hline \multicolumn{3}{|l|}{ Family background } \\
\hline Head of the household & 0.477 & 0.447 \\
\hline Number of kids in a household (hh) & 0.447 & 0.402 \\
\hline Number of inactive adults in a hh & 1.215 & 1.226 \\
\hline Earnings of other hh members & 1586.3 & 1782.7 \\
\hline \multicolumn{3}{|l|}{ Job characteristics } \\
\hline Work in 11 or more person establishment & 0.206 & 0.753 \\
\hline Excellent or good job characteristics & 0.861 & 0.922 \\
\hline Excellent or good workplace conditions & 0.869 & 0.930 \\
\hline Excellent or good employee relations & 0.891 & 0.948 \\
\hline Health benefits & 0.099 & 0.796 \\
\hline Dental benefits & 0.074 & 0.686 \\
\hline Vacation & 0.111 & 0.829 \\
\hline Incentive bonuses & 0.111 & 0.841 \\
\hline Maternity leave & 0.026 & 0.271 \\
\hline Unemployment benefits/pension & 0.099 & 0.783 \\
\hline Sick leave & 0.034 & 0.273 \\
\hline Transportation benefit & 0.064 & 0.543 \\
\hline Family subsidy & 0.033 & 0.428 \\
\hline Receive no benefits & 0.830 & 0.044 \\
\hline Job training & 0.169 & 0.364 \\
\hline Permanent position & 0.771 & 0.865 \\
\hline Normal hours worked in a week & 48.4 & 48.7 \\
\hline
\end{tabular}


Table 3a--Share of Informal Workers in Brazilian Manufacturing

\begin{tabular}{rr}
\hline \hline 1987 & 0.102 \\
1988 & 0.105 \\
1989 & 0.104 \\
1990 & 0.110 \\
1991 & 0.133 \\
1992 & 0.149 \\
1993 & 0.157 \\
1994 & 0.159 \\
1995 & 0.162 \\
1996 & 0.193 \\
1997 & 0.205 \\
1998 & 0.206 \\
& \\
Average & 0.149 \\
\hline \hline
\end{tabular}


Table 3b--Share of Informal Workers in Colombia

\begin{tabular}{rrr}
\hline \hline & All & Manufacturing \\
1986 & .58 & .47 \\
1988 & .57 & .45 \\
1990 & .57 & .47 \\
1992 & .56 & .46 \\
1994 & .52 & .42 \\
1996 & .61 & .57 \\
1998 & .59 & .54 \\
Average & .57 & .48 \\
\hline \hline
\end{tabular}


Table 3c--Decomposition of Changes in Informal Employment

\begin{tabular}{lrrr}
\hline \hline & & & \\
& Total & Within Industry & Between Industries \\
Brazil & .104 & .092 & .012 \\
Colombia & .012 & .020 & -.008 \\
Colombia--manufacturing only & .073 & .075 & -.002 \\
\hline \hline
\end{tabular}




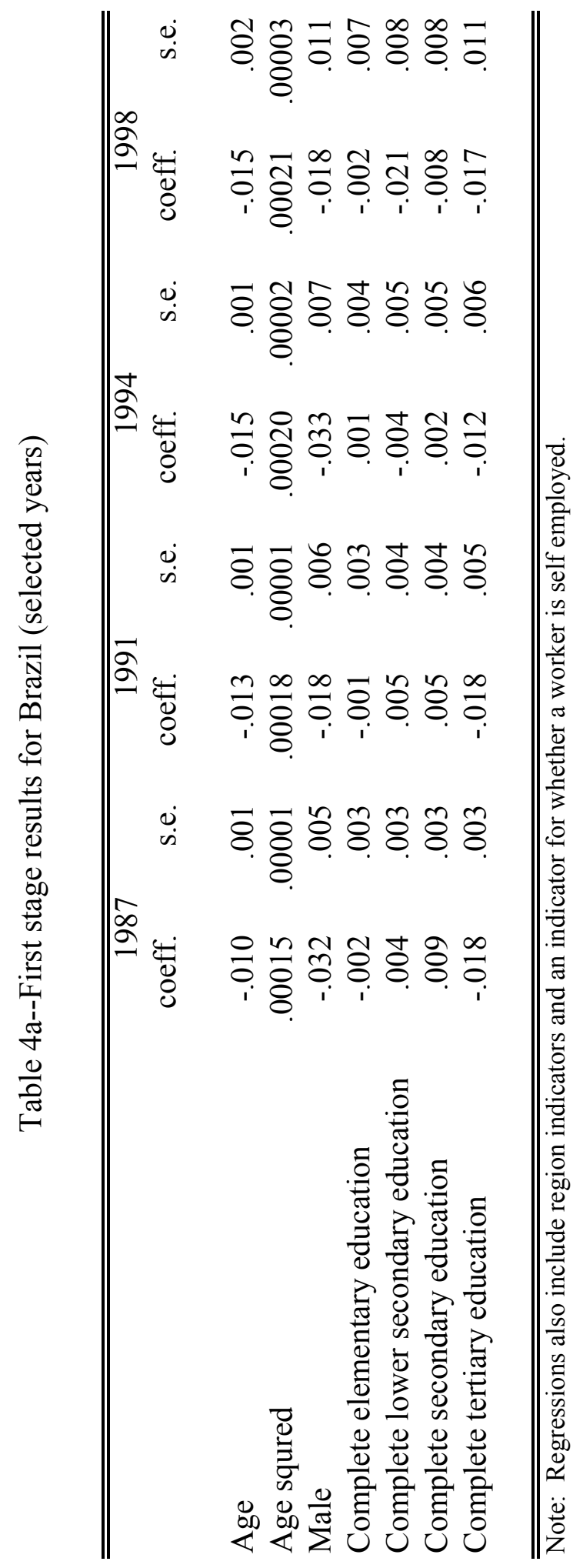




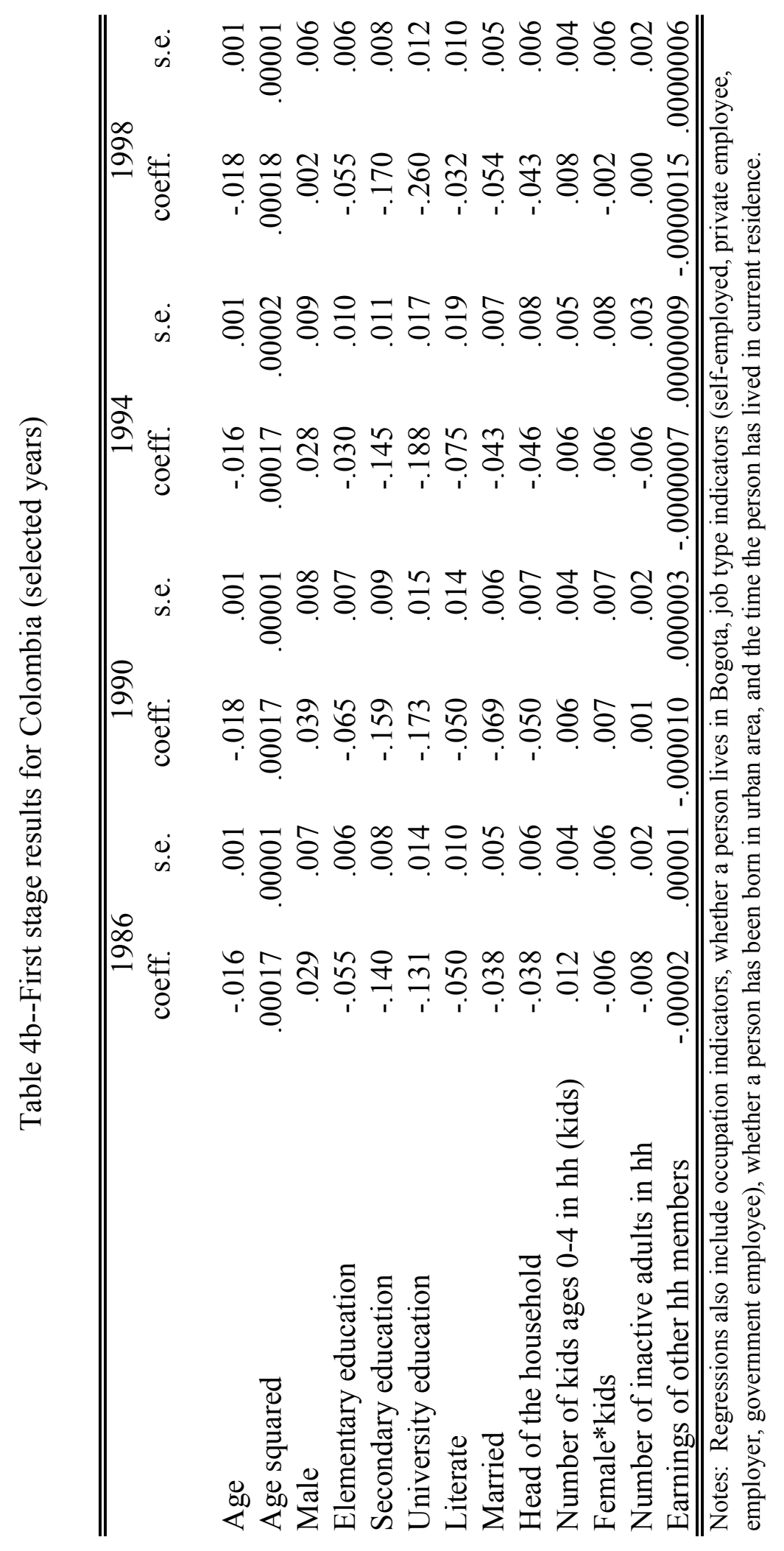




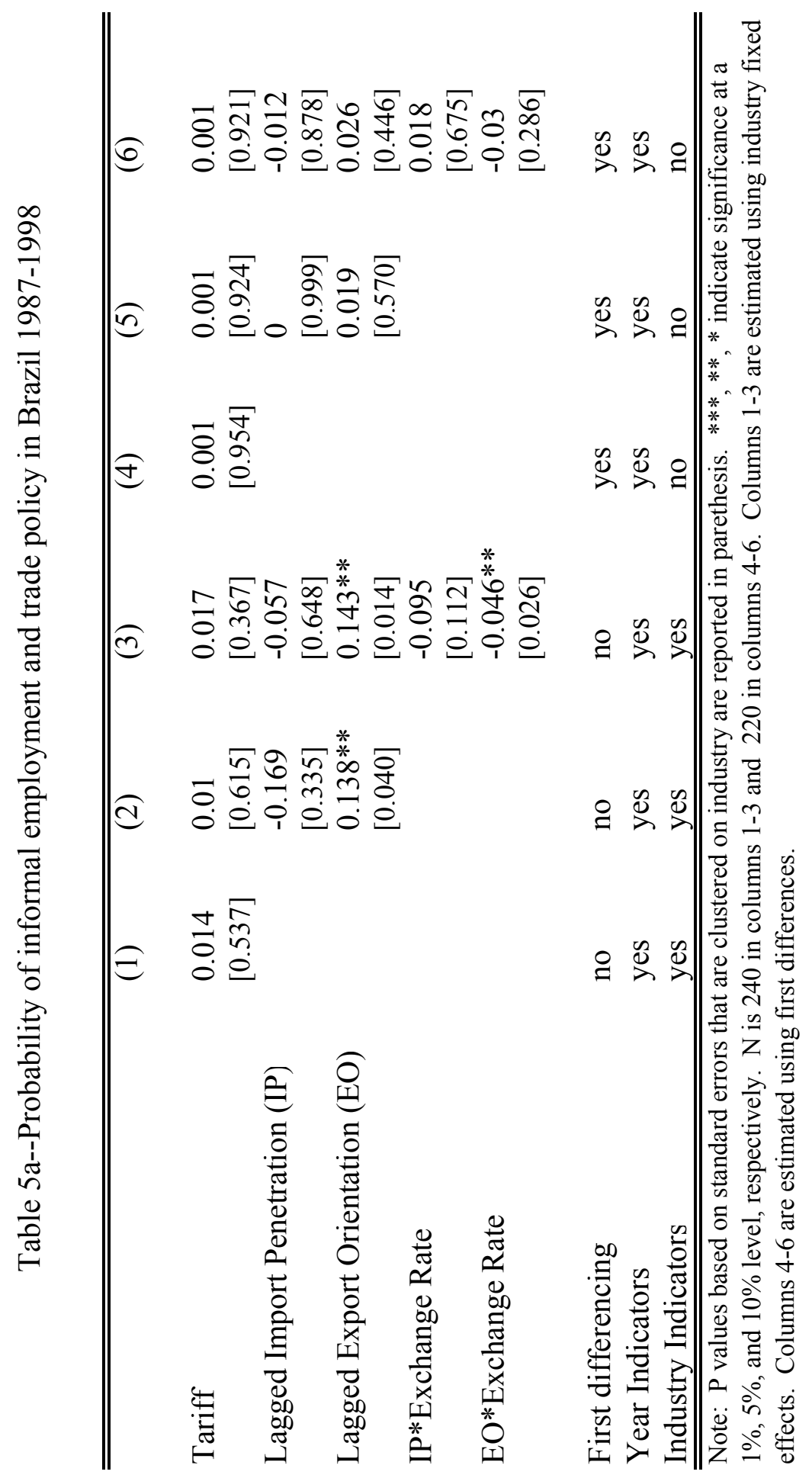




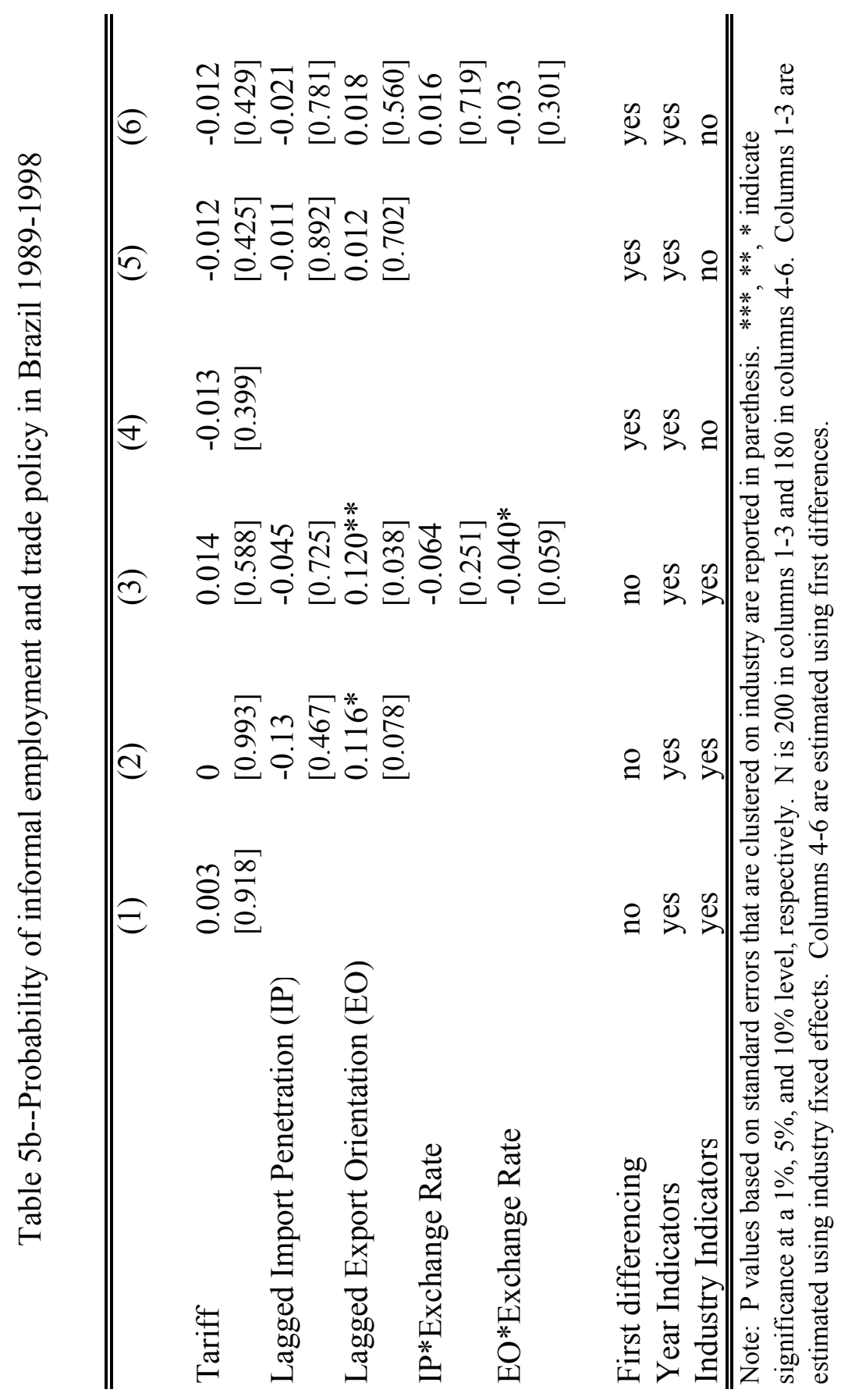




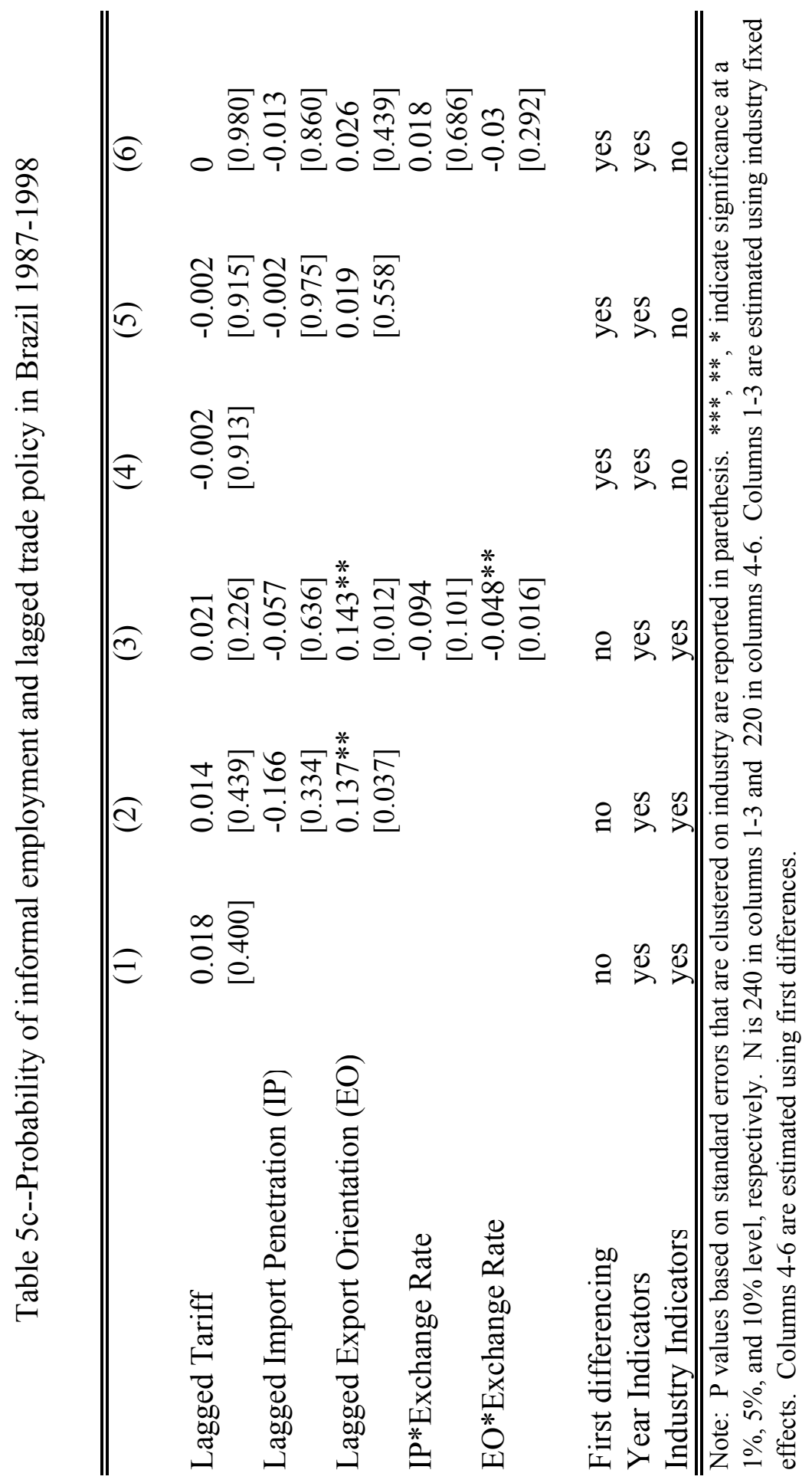




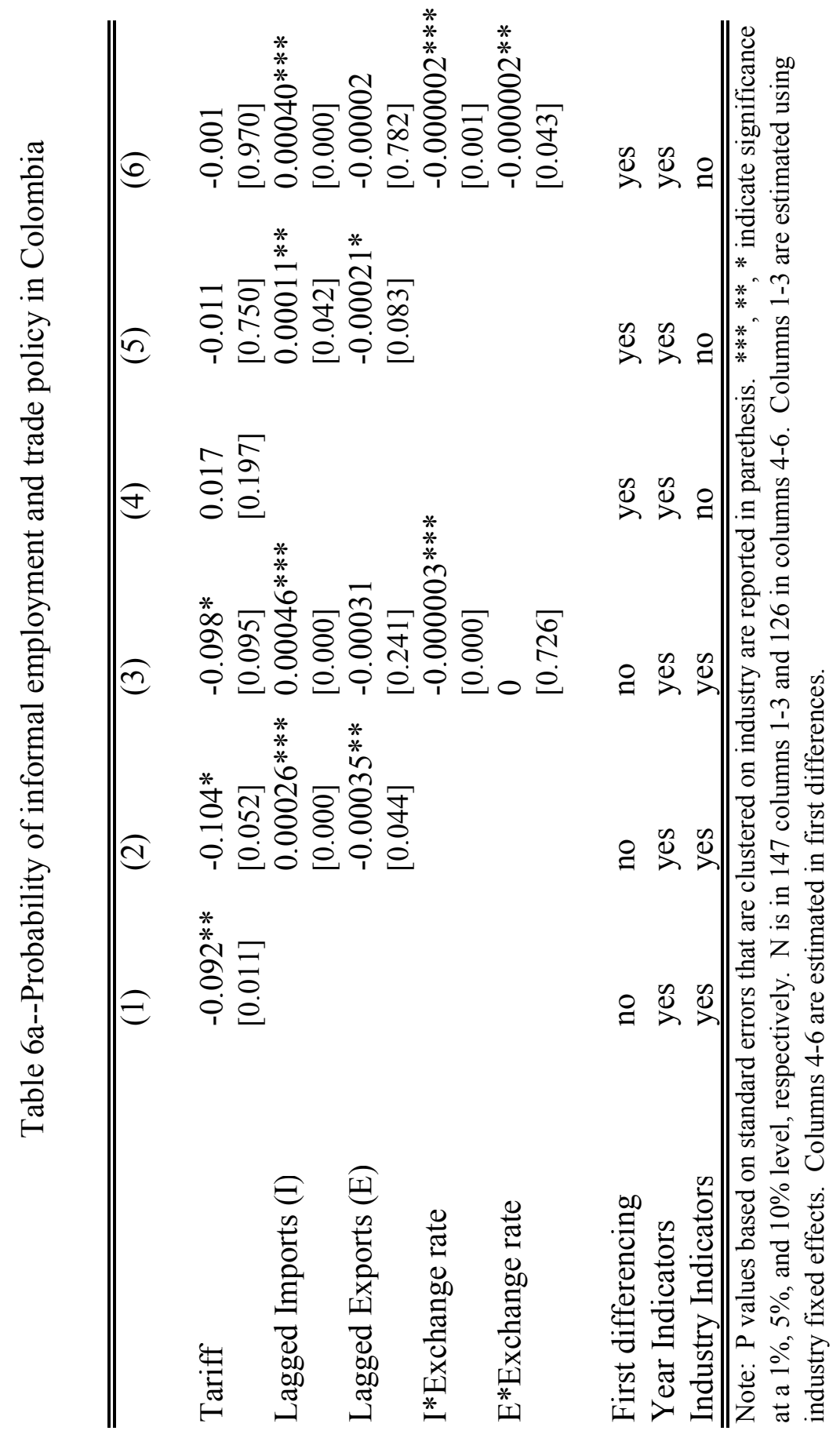




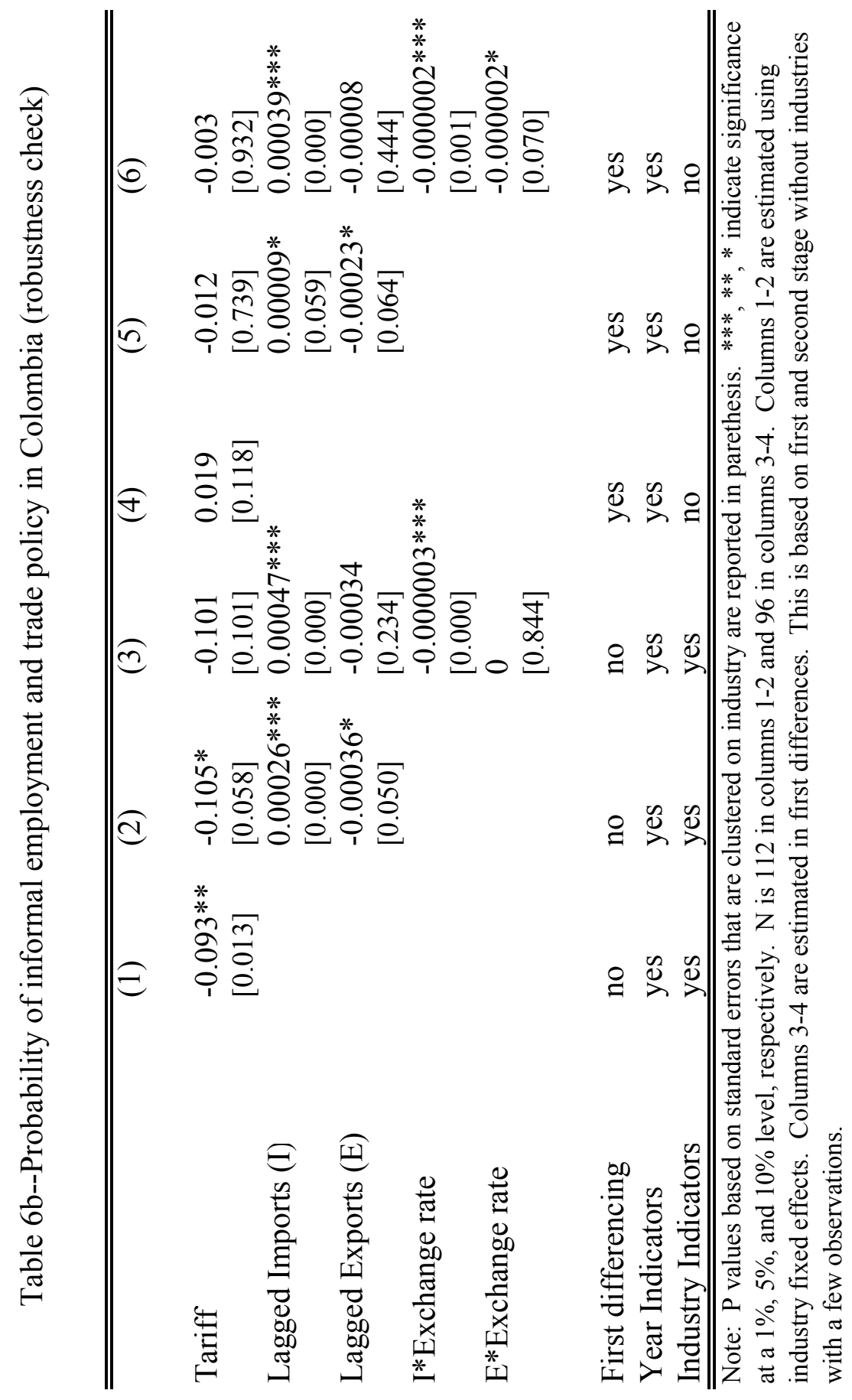




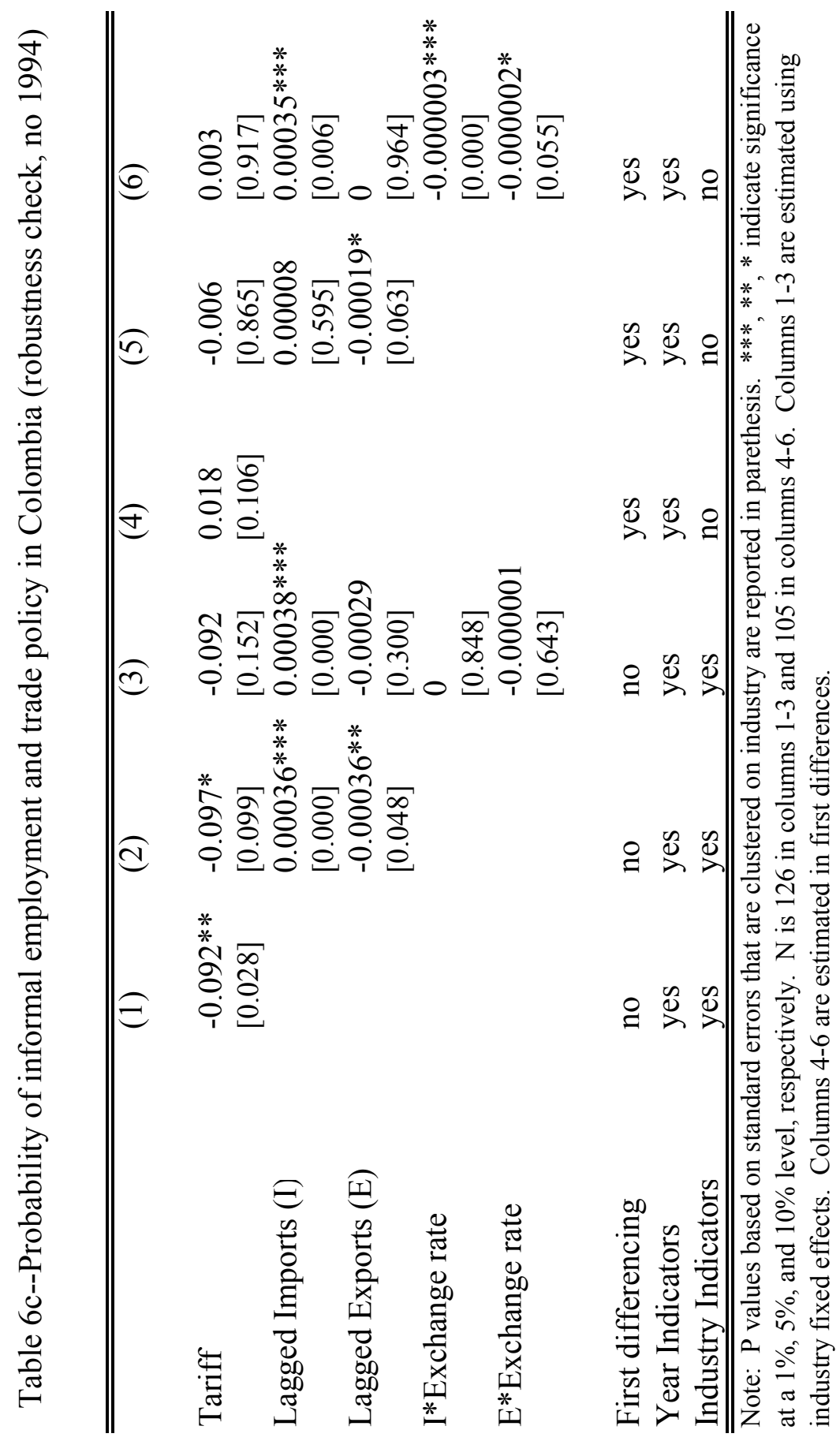




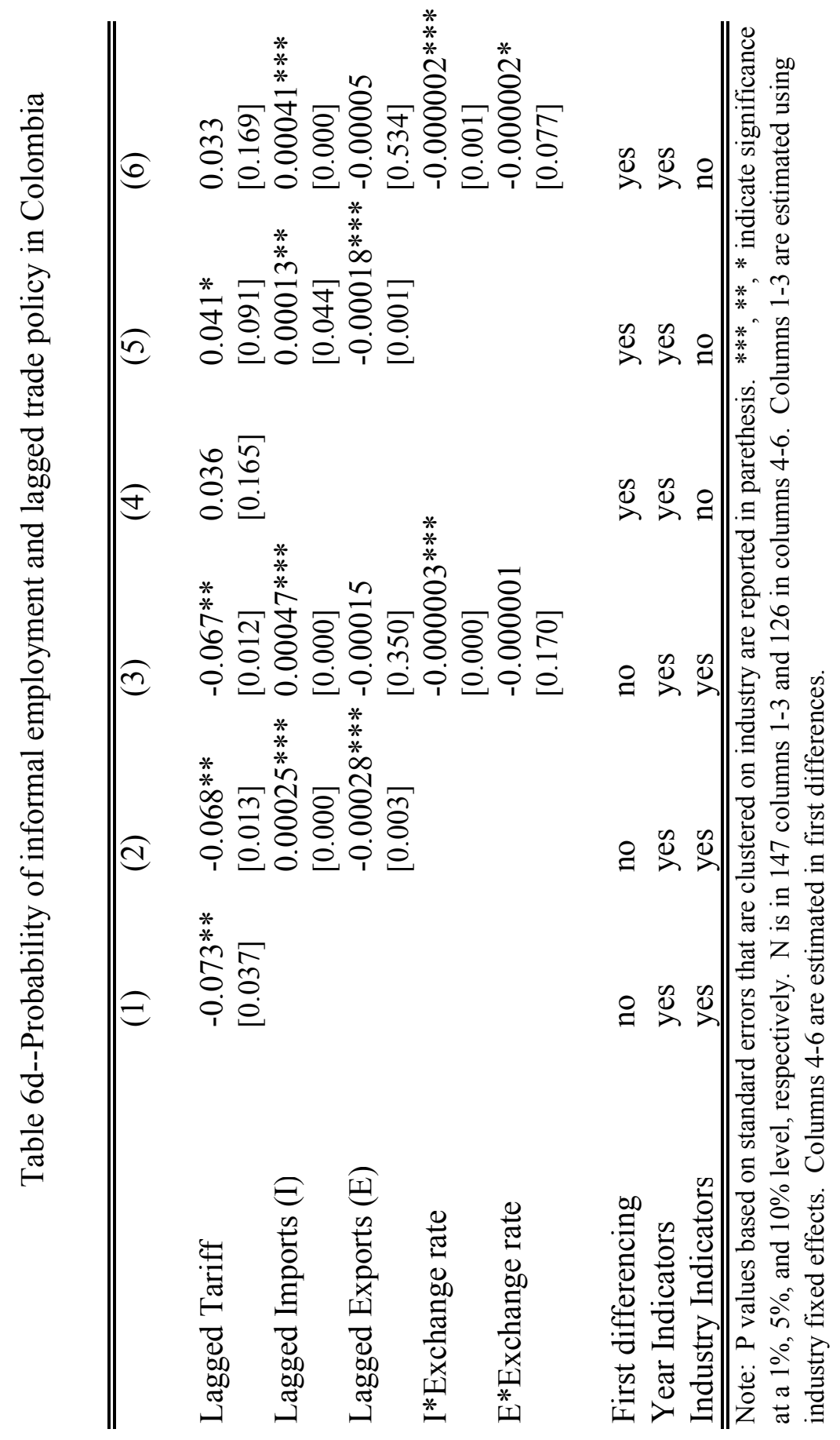




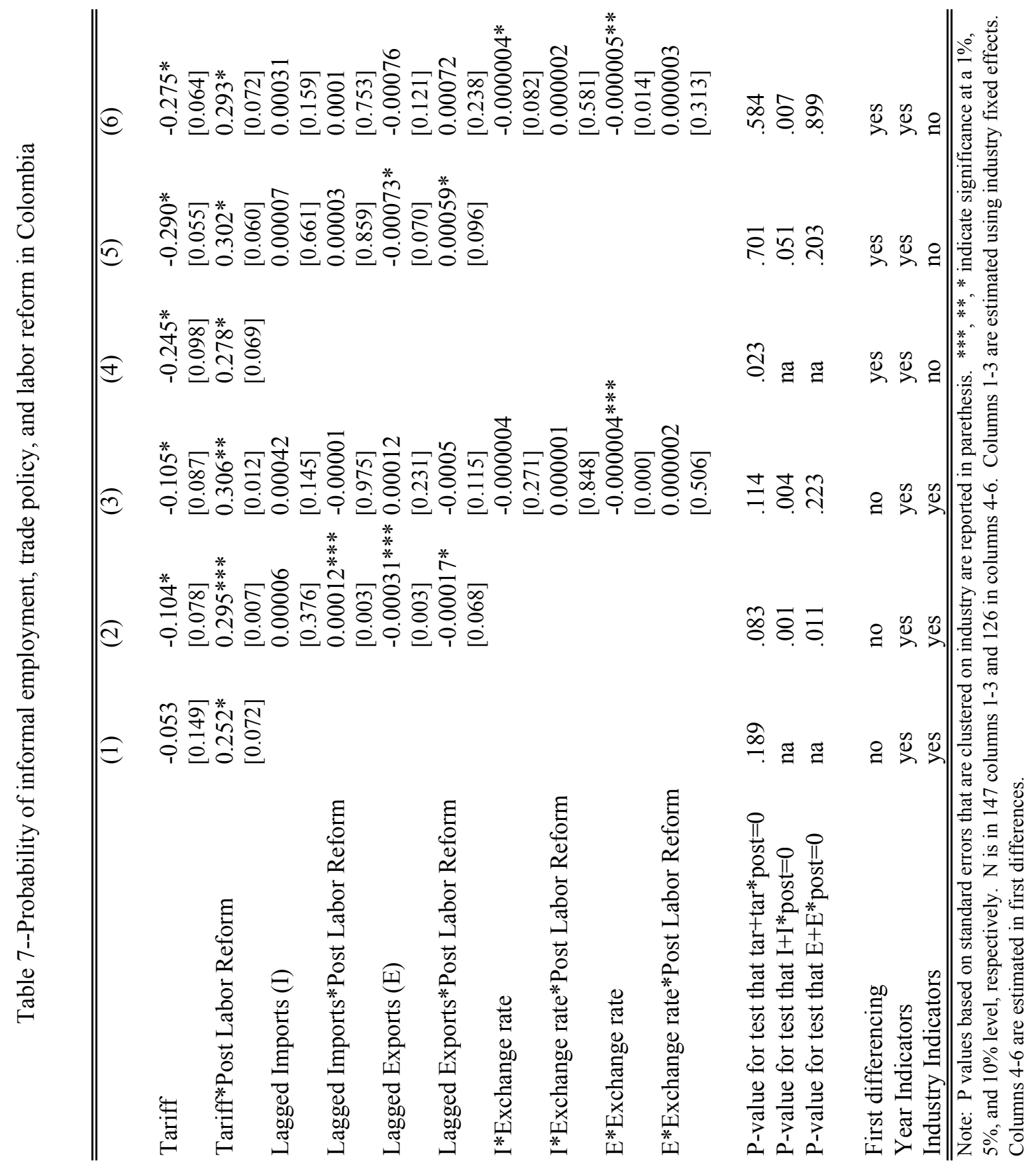

